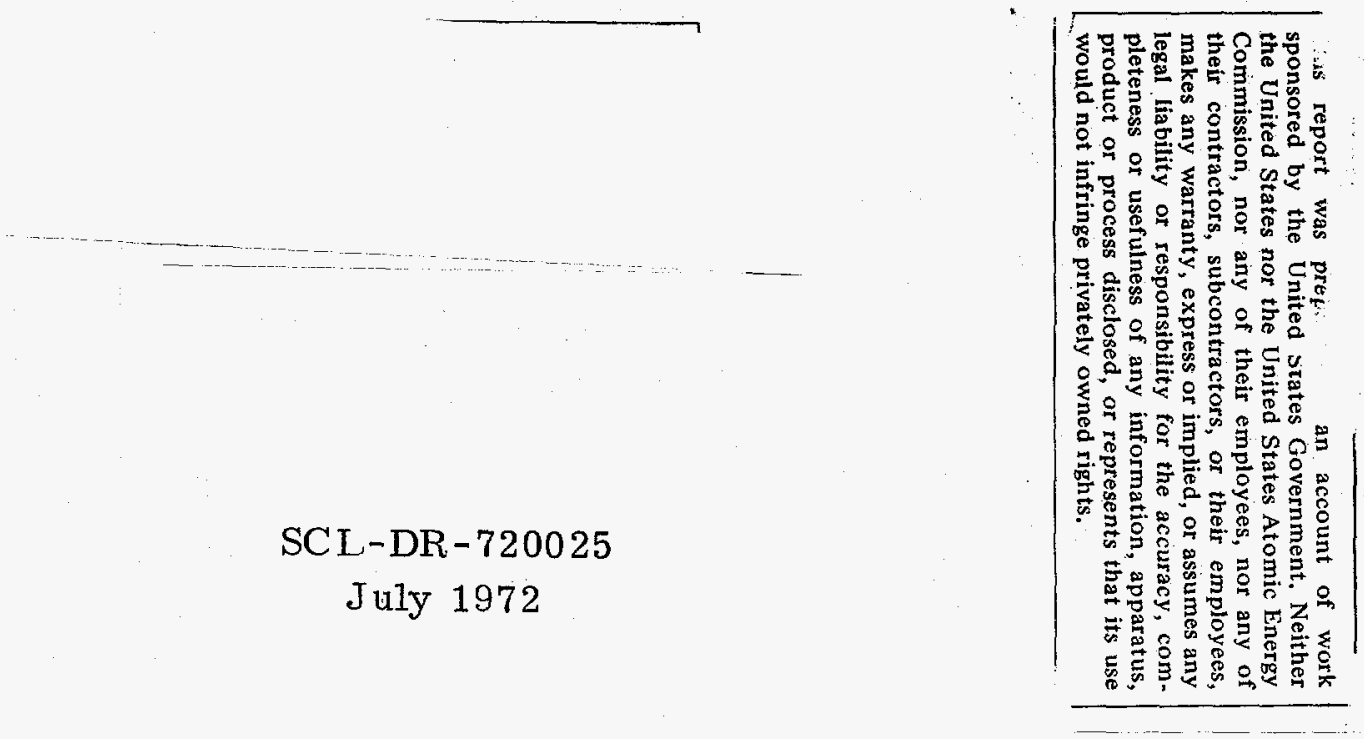

\title{
SPINFIN: A COMPUTER PROGRAM FOR TRAJECTORY SIMULATION OF FLIGHT VEHICLES WITH SEMI-PASSIVE ROLL CONTROL SYSTEMS
}

\author{
John K. Kryvoruka \\ Exploratory Development Division I, 8176 \\ Sandia Laboratories, Livermore
}

This report presents the trajectory computer program, SPINFIN. The program has been in use at Sandia Laboratories, Livermore, for flight simulation of those reentry vehicles which utilize a class of semi-passive fin roll-control systems. As such, it has served as an important design tool for some time. The report includes a presentation of the prominent features of the mathematical model which describes the vehicle aero-, flight-, and control-system dynamics. Additionally, detailed descriptions of the program input and output are provided as a user's guide.

\section{DISCLAIMER}

This report was prepared as an account of work sponsored by an agency of the United States Teither the United States Government nor any agency thereof, nor any of their employees, makes any warranty, express or implied, or assumes any legal liability or responsibility for the accuracy, completeness, or usefulness of any information, apparatus, product, or process disclosed, or represents that its use would not infringe privately owned rights. Referprocess disclose, or recific commercial product, process, or service by trade name, trademark, manufacturer, or otherwise does not necessarily constitute or imply its endorsement, recommendation, or favoring by the United States Government or any agency thereof. The views mendation, or favoring by the United States Gored herein do not necessarily state or reflect those of the United States Government or any agency thereof.

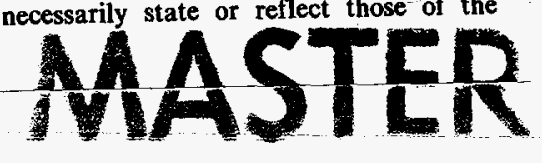




\section{DISCLAIMER}

Portions of this document may be illegible in electronic image products. Images are produced from the best available original document. 
CONTENTS

$\underline{\text { Page }}$

Introduction

Mathematical Model for the SPINFIN Trajectory Simulation Computer Program

Coordinates and Reference Frames

The Differential Equations of Vehicle Motion

The Differential Equations of Control Mass Motion

Specification of Aerodynamics

Description and User's Guide for the SPINFIN Trajectory Simulation Computer Program

Description of Problem Solution

General Description of Input

Detailed Description of Input

Description of Input for Sample Problem

Description of Output

Appendix A -- Summary of Governing Equations

References 


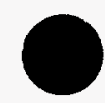

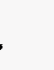




\section{ILLUSTRATIONS}

Figure

$\underline{\text { Page }}$

1. Inertial Reference Frame 18

2. Body Reference Frame 19

3. Orientation of Body-Fixed System Relative to Space-Fixed System 20

4. Conceptual SPINFIN Roll-Control System 28

5. Body-Fixed Axes and Control-Mass Axes 29

6. Representation of Geometric Fin Deflection versus Control-Mass Position 32

7. Cross-Velocity System 37

8. Cross-Spin System 37

9. Aerodynamic Variables 42

10. Fin Aerodynamic Force System 44

11. Description of Polynomial Input 60

12. Description of Single Table Input 63

13. Description of Double Table Input 67

14. Center-of-Mass Variation 71

15. Description of Altitude-Dependent Effects Input 73

16. Description of Input for Sample Problem 75-77 


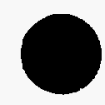




\section{TABLES}

$\underline{\text { Page }}$

I. Description of Vehicle Aerodynamic Coefficients

II, Description of Aerodynamic Coefficients Used with Fin Aerodynamic Coefficient Input

III. Tabular Representation of Aerodynamic Coefficient Data versus Mach Number

IV. Tabular Representation of Aerodynamic Coefficient Data versus Mach Number and Angle-of-Attack

V. Altitude-Dependent Effects Data

VI. Standard Output Variables

VII. Supplemental Output Variables 80-82

VIII. Standard Plot Variables 


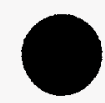




\section{LIST OF SYMBOLS}

$\mathrm{x}, \mathrm{y}, \mathrm{z} \quad$ Axes or coordinates in fixed reference frame (Figure 1)

$\mathrm{X}, \mathrm{Y}, \mathrm{Z} \quad$ Axes or coordinates in moving body frame (Figure 2)

$\mathrm{X}$-axis Longitudinal axis of missile geometric symmetry

$\mathrm{Z}$-axis Normal to $\mathrm{X}-\mathrm{Z}$ plane

$\theta, \psi, \phi \quad$ Eulerian angles (Figure 3)
$A=A_{X X} A_{X Y} A_{X Z}$ $\left.A_{Y X}{ }^{A}{ }_{Y Y}^{A}{ }_{Y Z}\right\}$ Matrix of direction cosines. The elements are $A_{Z X} A_{Z Y} A_{Z Z}$ the cosines of the angles between the inertial and body-fixed frames.

$\mathrm{A}^{\mathrm{T}}$

Transpose of $\mathrm{A}$

$A^{-1}$

Inverse of $\mathrm{A}$

$\lambda_{0}$

$\lambda_{1}$

$\lambda_{2}$

$\lambda_{3}$

$\overrightarrow{\mathrm{R}}$

Body center-of-mass position vector in body $X, Y, Z$ axes

$\left.\begin{array}{c}\mathrm{x}_{0} \\ \mathrm{y}_{0} \\ \mathrm{z}_{0}\end{array}\right\}$

$\overrightarrow{\mathrm{V}}$

Total velocity vector - - ft/s

Elements of a unimodular quaternion or versor which corresponds to that rotation which brings the inertial frame into coincidence with the moving body frame.

Body center-of-mass displacements from body axes reference point along $X, Y, Z$ axes, respectively -- ft 
$\left.\begin{array}{l}u \\ v \\ w\end{array}\right\}$

Components of total velocity along body $\mathrm{X}, \mathrm{Y}, \mathrm{Z}$ axes, respectively -- $\mathrm{ft} / \mathrm{s}$

$\vec{\omega}, \vec{\Omega}$

Body angular velocity vector -- $\mathrm{rad} / \mathrm{s}$

$\left.\begin{array}{l}p \\ q \\ r\end{array}\right\}$

Components of the angular velocity vector along body $\mathrm{X}, \mathrm{Y}, \mathrm{Z}$ axes, respectively -- $\mathrm{rad} / \mathrm{s}$

Total applied force vector

$\left.\begin{array}{l}F_{X} \\ F_{Y} \\ F_{Z}\end{array}\right\}$

Applied forces along $X, Y, Z$ axes, respectively -- $1 \mathrm{~b}$

$\bar{I}$

Missile moment of inertia tensor (Equation 9)

I Xx

Roll moment of inertia

$\mathrm{I}_{\mathrm{YY}}$

Pitch moment of inertia

Yaw moment of inertia

$I_{Z Z}$

slug-ft ${ }^{2}$

$\mathrm{I}_{\mathrm{XY}}$

$\left.I_{X Z}\right\} \quad$ Products of inertia -- slug- $\mathrm{ft}^{2}$

$I_{Y Z}$

$\overrightarrow{\mathrm{M}}$

Total applied moment vector about reference point

$\left.\begin{array}{l}\mathrm{L} \\ \mathrm{M} \\ \mathrm{N}\end{array}\right\}$

Applied moments along $X, Y, Z$ axes, respectively -- $\mathrm{ft}-\mathrm{lb}$

$\left.\begin{array}{c}C_{X} \\ C_{Y} \\ C_{Z}\end{array}\right\}$

Aerodynamic force coefficients along the $X, Y, Z$ axes 


$$
\left.\begin{array}{c}
\mathrm{C}_{1} \\
\mathrm{C}_{\mathrm{m}} \\
\mathrm{C}_{\mathrm{n}}
\end{array}\right\}
$$

Q

$\mathrm{m}$

d

$\mathrm{g}$

$$
\left.\begin{array}{l}
F_{x g} \\
F_{y g} \\
F_{z g}
\end{array}\right\}
$$

$\left.\begin{array}{l}x \\ y\end{array}\right\}$ $\left.\begin{array}{c}\mathrm{X}_{\mathrm{m}} \\ \mathrm{Y}_{\mathrm{m}} \\ \mathrm{Z}_{\mathrm{m}}\end{array}\right\}$

$\overrightarrow{\mathrm{F}}_{\mathrm{m}}$

$$
\left.\begin{array}{l}
F_{\text {xm }} \\
F_{y m} \\
F_{z m}
\end{array}\right\}
$$

$\bar{m}$
Aerodynamic moment coefficients along the $X, Y, Z$ axes. (The coefficients are expanded in Equation (70) and described in detail in Table I.)

Dynamic pressure -- $1 \mathrm{~b} / \mathrm{ft}^{2}$

Vehicle mass -- slugs

Missile diameter and reference length -- ft

Reference area $S=\frac{\pi \mathrm{d}^{2}}{4} \mathrm{ft}^{2}$

Acceleration due to gravity -- ft/ $\mathrm{s}^{2}$

Components of $\mathrm{mg}$ along body $\mathrm{X}, \mathrm{Y}, \mathrm{Z}$ axes, respectively -- $1 \mathrm{~b}$

Vehicle velocity components along inertial $\mathrm{x}, \mathrm{y}, \mathrm{z}$ axes, respectively - - ft/s

Control mass position vector in $\mathrm{X}, \mathrm{Y}, \mathrm{Z}$ system

Components of control mass position along $X, Y, Z$ axes - - ft

Total applied force on control mass

Components of applied force on control mass along $\mathrm{X}, \mathrm{Y}, \mathrm{Z}$ axes - - $1 b$

Control mass -- slugs 


$$
\begin{aligned}
& \left.\begin{array}{c}
X_{c} \\
Y_{c} \\
Z_{c}
\end{array}\right\} \\
& \left.\begin{array}{l}
\phi_{c} \\
\psi_{c}
\end{array}\right\} \\
& \text { Orientation angles which locate control mass axes } \\
& \text { relative to body axes } \\
& \vec{V}_{c} \\
& \text { Vehicle total velocity in } X_{c}, Y_{c}, Z_{c} \text { system } \\
& \left.\begin{array}{c}
\mathrm{u}_{\mathrm{c}} \\
\mathrm{v}_{\mathrm{c}} \\
\mathrm{w}_{\mathrm{c}}
\end{array}\right\} \\
& \vec{\Omega}_{c} \\
& \text { Vehicle total angular velocity in } X_{c}, Y_{c}, Z_{c} \text { system -- rad/s } \\
& \left.\begin{array}{l}
p_{c} \\
q_{c} \\
r_{c}
\end{array}\right\} \\
& \overrightarrow{\mathrm{R}}_{\mathrm{m}} \\
& \left.\begin{array}{l}
\mathrm{x}_{\mathrm{m}_{\mathrm{c}}} \\
\mathrm{y}_{\mathrm{m}_{\mathrm{c}}} \\
\mathrm{z}_{\mathrm{m}_{\mathrm{c}}}
\end{array}\right\} \\
& \text { Components of total velocity along } X_{c}, Y_{c}, Z_{c} \text { axes -- } \mathrm{ft} / \mathrm{s} \\
& \text { Components of angular velocity along } X_{c}, Y_{c}, Z_{c} \text { system -- rad/s } \\
& \text { k } \\
& \text { Control system spring constant -- } 1 \mathrm{~b} / \mathrm{ft} \\
& \text { c Control system damping coefficient -- } 1 \mathrm{~b}-\mathrm{s} / \mathrm{ft} \\
& \mathrm{F}_{\text {Aero }} \\
& \text { Control mass position in } X_{c}, Y_{c}, Z_{c} \text { system } \\
& \text { Components of control mass position along } X_{c}, Y_{c}, Z_{c} \text { axes -- ft } \\
& \text { Aerodynamic feedback force on control mass -- lb }
\end{aligned}
$$


$\mathrm{f}_{\mathrm{m}}$

$\delta$

$\phi_{\text {L }}$

$\epsilon$

$\mathrm{C}_{\mathrm{F}}$

${ }^{\mathrm{C}_{\mathrm{F}}}$

$\vec{\alpha}$

$\hat{\phi}$

$\alpha$

$\beta$

$\vec{q}$

$\widetilde{\phi}$

${ }^{\mathrm{C}_{\mathrm{F}}}$

$\mathrm{C}_{\mathrm{D}}$

$\overrightarrow{\mathrm{R}}_{\mathrm{F}}$

$\left.\begin{array}{c}{ }^{x_{F}} \\ y_{F} \\ z_{F}\end{array}\right\}$

Control system friction force - - lb

Geometric fin deflection angle relative to body centerline -- deg or rad

Control system linkage constant relating fin rotation to linear mass motion -- $\mathrm{rad} / \mathrm{ft}$

Fin aerodynamic center-of-pressure off set from fin hinge line - - ft

Fin force coefficient normal to fin centerline

Fin force coefficient parallel to fin centerline

Vehicle total angle-of-attack -- deg or rad

Aerodynamic roll angle -- rad

Angle-of-attack in body axes -- rad or deg

Angle of side slip in body axes -- rad or deg

Magnitude of cross spin -- $\mathrm{rad} / \mathrm{s}$

Cross-spin orientation angle -- rad

Fin force coefficient normal to vehicle centerline

Fin force coefficient parallel to vehicle centerline

Fin aerodynamic center-of-pressure position in $X, Y, Z$ axes

Components of fin aerodynamic center-of-pressure in body $X, Y, Z$ axes 


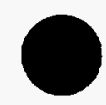




\section{SPINFIN: A COMPU'TER PROGRAM FOR TRAJECTORY SIMULATION OF FLIGHT VEHICLES WITH SEMI-PASSIVE ROLL CONTROL SYSTEMS}

Introduction

This report describes the important features of the trajectory simulation computer program, SPINFIN. Unique to the program is the capability to account for and include in the trajectory simulation the effects of a class of semi-passive fin roll-control systems. This presentation is an extension and implementation of the detailed mathematical model developed in Reference 1. The salient aspects of the model, including a detailed description of the control system, equations of motion, and a comprehensive aerodynamic model, are reproduced herein. In addition, the report is designed to serve as a program user's guide and, as such, provides a detailed description of program input, output, etc.

The simulation code was created as part of and in support of the rollcontrol design and development program at Sandia Laboratories, Livermore (SLL). This effort is directed toward the analysis ${ }^{2}$, design and development 3,4 , and flight test ${ }^{5}$ of a centrifugally actuated fin roll-control system. Included in the fin roll-control study program has been the development of analytic methods to describe the complex aerodynamics associated with finned bodies 6,7 , experimental verification ${ }^{8}$, and the influence of fins and fin roll control on the vehicle flight dynamics. 9,10 The roll-control development program has also included considerable design, development, and testing of fin roll-control systems.

The major features of the model used in the computer program include an Adams-Moulton predictor-corrector integration scheme, a unimodular quaternion (versor) angular substitution, an extensive capability for aerodynamic characteristics, and a detailed specification of the control-system mechanics. The fin and vehicle aerodynamic characteristics may be nonlinear functions of angle-of-attack, Mach number, roll orientation, and geometric fin deflection. The contributions due to cross-velocity and crossspin are accounted for by expanding the coefficients as truncated Fourier functions of the roll angle. In addition, all aerodynamic characteristics as well as vehicle mass properties are allowed to vary with altitude in order to more closely simulate the effects of fin ablation, nose and heatshield erosion, boundary layer transition, etc. Atmospheric properties may be 
obtained either from a user-written subroutine or from an optional ARDC 1962 model atmosphere subroutine which is included in the program. The control system model includes friction, aerodynamic feedback, etc., but the control system is regarded as a lumped parameter model.

The program is written for the CDC 6600 and has been operational for some time. It has served as a design tool in the development of the rollcontrol concepts. Recently, significant progress has been made toward implementing the model on the SLL hybrid computer.

Mathematical Model for the SPINFIN Trajectory Simulation Computer Program

Coordinates and Reference Frames

Two right-handed coordinate systems are used to specify the six degrees of freedom (translational plus rotational) of the flight vehicle as well as the additional degrees of freedom of control masses internal to the body. (An additional coordinate system will be introduced later which will facilitate the specification of the control mass equations of motion.) The position of the vehicle in space is specified by the three translational coordinates $x, y, z$ relative to an inertial reference frame fixed in space with origin, $0^{\prime}$, at the center of a spherical, non-rotating earth. This system is described in Figure 1.

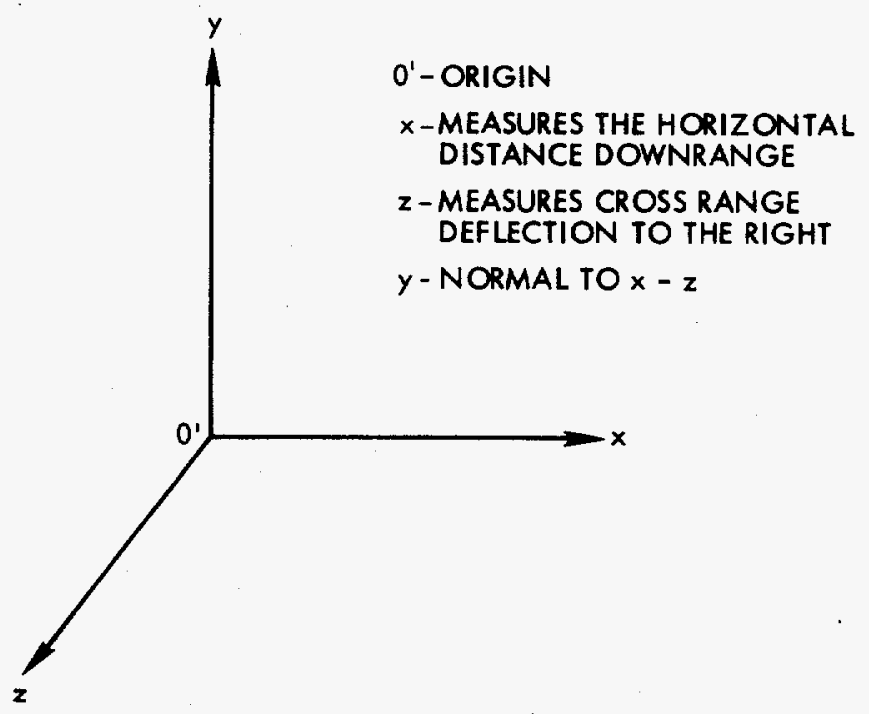

Figure 1. Inertial Reference Frame 
In addition to the three translational coordinates, three independent angular coordinates are necessary to define the orientation of the vehicle in space. These coordinates are specified by the angular position of a right-handed, body-fixed reference frame relative to the inertial frame. This body-fixed coordinate system has origin 0 , and is designated $X, Y, Z$ as shown in Figure 2. Although the position and orientation of this system relative to the body are arbitrary, the system is chosen so that the X-axis corresponds to the longitudinal axis of geometric symmetry of the body as defined by the outer surface of the body, provided such symmetry exists. The $Z$-axis is parallel to a fin of the missile, and $Y$ is normal to the $X, Z$ plane, thus forming an orthogonal triad. The origin of the system is taken, in general, as the point about which the aerodynamic coefficients are known.

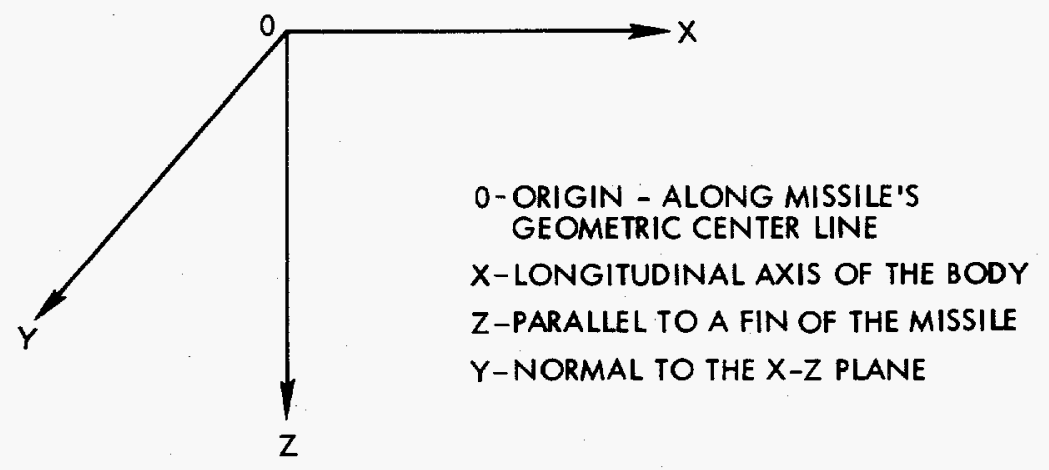

Figure 2. Body Reference Frame

The mass, aerodynamic and inertia characteristics of the vehicle are defined in the $X, Y, Z$ frame.

The most commonly used method of specifying direction cosines is a system of Eulerian angular coordinates. In Figure 3, the body axis system is oriented relative to the space fixed system by a set of modified Euler angles. These are three ordered rotations $\psi, \theta$, and $\phi$ (as shown). Therefore, the transformation matrix, A, of direction cosines relating the missile fixed axes to the inertial axes in terms of the modified Euler angles is given

$$
\left(\begin{array}{l}
X \\
Y \\
Z
\end{array}\right)=A\left(\begin{array}{l}
x \\
y \\
z
\end{array}\right)
$$




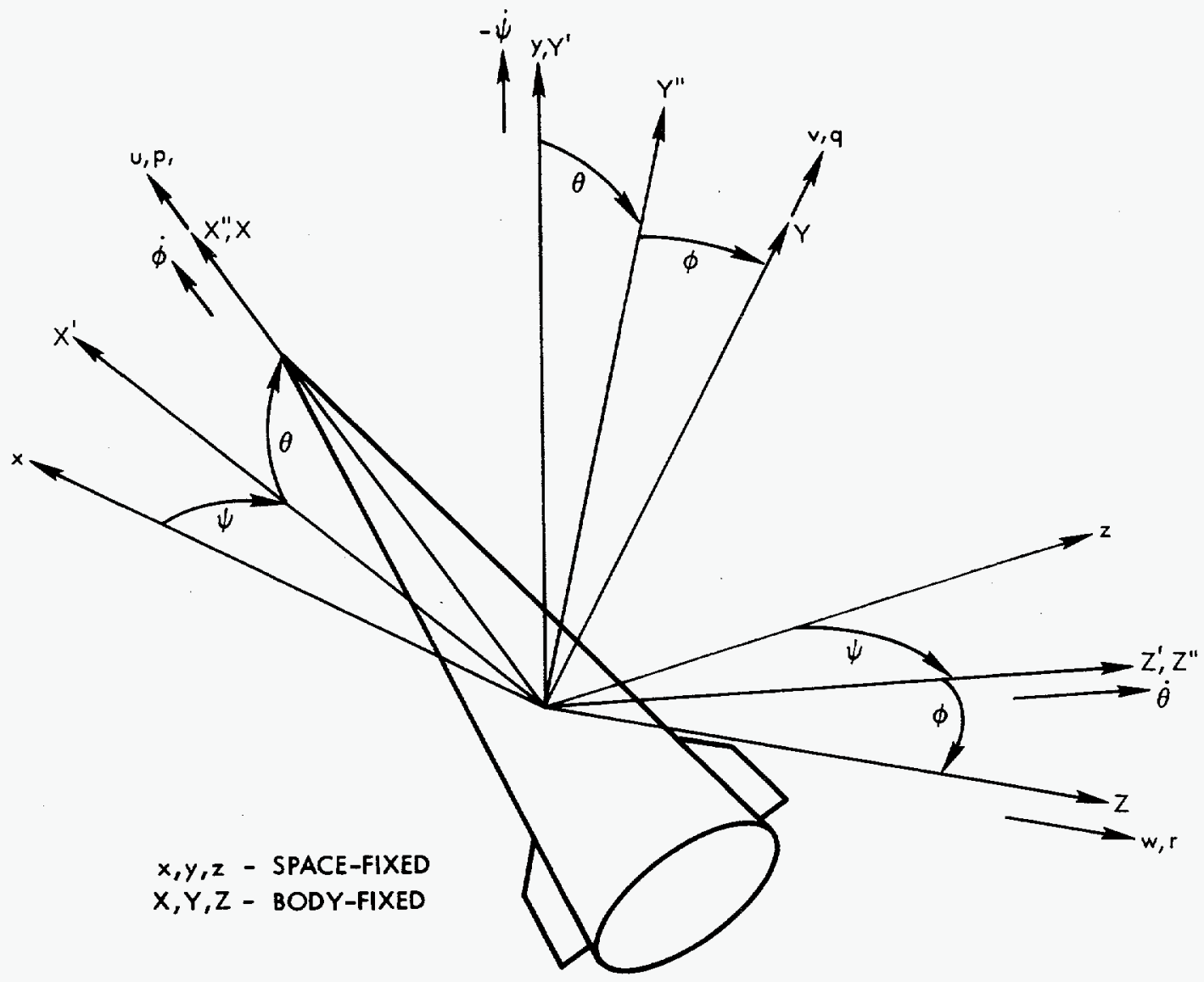

Figure 3. Orientation of Body-Fixed System Relative to Space-Fixed System 
where $A$ is expressed

$A=\left(\begin{array}{lll}\cos \psi \cos \theta & \sin \theta & \cos \theta \sin \psi \\ -\sin \phi \sin \psi-\cos \phi \cos \psi \sin \theta & \cos \phi \cos \theta & \sin \phi \cos \psi-\cos \phi \sin \psi \sin \theta \\ -\cos \phi \sin \psi+\sin \phi \cos \psi \sin \theta & -\sin \phi \cos \theta & \cos \phi \cos \psi+\sin \phi \sin \psi \sin \theta\end{array}\right)$

$A=\left(\begin{array}{lll}A_{X X} & A_{X Y} & A_{X Z} \\ A_{Y X} & A_{Y Y} & A_{Y Z} \\ A_{Z X} & A_{Z Y} & A_{Z Z}\end{array}\right)$

The vehicle's angular velocity may be given in terms of the modified Euler angles and their derivatives. Unfortunately, the equations are singular for values of the pitch angle $\theta$ which are odd multiples of $\pi / 2$. Additionally, the presence of this singularity leads to considerable truncation error in the neighborhood of the singularity.

An alternate form of the transformation matrix which eliminates the aforementioned difficulties will therefore be developed. This new matrix will be developed in terms of the components of a unimodular quaternion (or versor) as angular coordinates.

The elements $\lambda_{0}, \lambda_{1}, \lambda_{2}, \lambda_{3}$, of a versor

$$
\lambda=\lambda_{0}+i \lambda_{1}+j \lambda_{2}+k \lambda_{3}
$$

may be expressed in terms of the direction of the axis and the magnitude of that rotation which carries the inertial frame into the body frame; they are related to the Euler angles by the following:

$\lambda_{0}=\cos \phi / 2 \cos \theta / 2 \cos \psi / 2+\sin \phi / 2 \sin \theta / 2 \sin \psi / 2$

$\lambda_{1}=-\cos \phi / 2 \sin \theta / 2 \sin \psi / 2+\sin \phi / 2 \cos \theta / 2 \cos \psi / 2$

$\lambda_{2}=-\cos \phi / 2 \cos \theta / 2 \sin \psi / 2+\sin \phi / 2 \sin \theta / 2 \cos \psi / 2$

$\lambda_{3}=\cos \phi / 2 \sin \theta / 2 \cos \psi / 2+\sin \phi / 2 \cos \theta / 2 \sin \psi / 2$ 
The transformation matrix, A, may then be expressed in terms of the versor elements by

$$
A=\left(\begin{array}{lll}
2\left(\lambda_{0}^{2}+\lambda_{1}^{2}\right)-1 & 2\left(\lambda_{1} \lambda_{2}+\lambda_{0} \lambda_{3}\right) & 2\left(\lambda_{1} \lambda_{3}-\lambda_{0} \lambda_{2}\right) \\
2\left(\lambda_{1} \lambda_{2}-\lambda_{0} \lambda_{3}\right) & 2\left(\lambda_{0}^{2}+\lambda_{2}^{2}\right)-1 & 2\left(\lambda_{2} \lambda_{3}+\lambda_{0} \lambda_{1}\right) \\
2\left(\lambda_{1} \lambda_{3}+\lambda_{0} \lambda_{2}\right) & 2\left(\lambda_{2} \lambda_{3}-\lambda_{0} \lambda_{1}\right) & 2\left(\lambda_{0}^{2}+\lambda_{3}^{2}\right)-1
\end{array}\right)
$$

Conversely, the attitude of the vehicle in space as given by the modified Euler angles is determined from the following relations

$$
\begin{aligned}
& \psi=\tan ^{-1}\left\{\frac{2\left(\lambda_{1} \lambda_{3}-\lambda_{0} \lambda_{2}\right)}{2\left(\lambda_{0}^{2}+\lambda_{1}^{2}\right)-1}\right\}=\tan ^{-1}\left(\frac{A_{X Z}}{A_{X X}}\right) \\
& \theta=\sin ^{-1}\left\{2\left(\lambda_{1} \lambda_{2}+\lambda_{0} \lambda_{3}\right)\right\}=\sin ^{-1}\left(A_{X Y}\right) \\
& \phi=\tan ^{-1}\left\{\frac{2\left(\lambda_{0} \lambda_{1}-\lambda_{2} \lambda_{3}\right.}{2\left(\lambda_{0}^{2}+\lambda_{2}^{2}\right)-1}\right\}=\tan ^{-1}\left(\frac{-A_{Z Y}}{A_{Y Y}}\right)
\end{aligned}
$$

$\underline{\text { The Differential Equations of Vehicle Motion }}$

As stated previously, the equations of motion are developed in terms of quantities known in the body $\mathrm{X}, \mathrm{Y}, \mathrm{Z}$ coordinate system. The body system is also used for specifying the vehicle's aerodynamic, mass, and inertial properties. Two groups of equations are developed. The first set governs the motion of the vehicle in space as a rigid body while the second group describes the dynamical relations of the control masses relative to the body.

The equations of motion which describe the six degrees of freedoms of the vehicle in space are developed in considerable detail in Reference 1. The vector form of these equations as so derived are given as

$$
\vec{F}=m[\dot{\vec{V}}+\vec{\Omega} \times \vec{V}+\dot{\vec{\Omega}} \times \vec{R}+\vec{\Omega} \times(\vec{\Omega} \times \vec{R})]
$$


and

$$
\overrightarrow{\mathrm{M}}=\overline{\overline{\mathrm{I}}} \dot{\bar{\Omega}}+\vec{\Omega} \times \overline{\overline{\mathrm{I}}} \vec{\Omega}+\overrightarrow{\mathrm{R}} \times \mathrm{m}(\overrightarrow{\mathrm{V}}+\vec{\Omega} \times \overrightarrow{\mathrm{V}})
$$

in which $\vec{F}$ and $\vec{M}$ are the applied force and moment vectors respectively.

In these equations, the linear and angular velocities and accelerations are those of the body in space with components resolved along the body $\mathrm{X}, \mathrm{Y}$, $Z$ axes:

$$
\begin{aligned}
& \vec{V}=u \vec{i}+v \vec{j}+w \vec{k} \\
& \dot{\vec{V}}=\dot{u} \vec{i}+v \vec{j}+\dot{w k} \\
& \vec{\Omega}=p \vec{i}+q \vec{j}+r \vec{k} \\
& \dot{\vec{\Omega}}=\dot{p} \vec{i}+\dot{q} \vec{j}+\dot{r} \vec{k}
\end{aligned}
$$

and the position of the center-of-mass is expressed

$$
\overrightarrow{\mathrm{R}}=\mathrm{x}_{0} \overrightarrow{\mathrm{i}}+\mathrm{y}_{0} \overrightarrow{\mathrm{j}}+\mathrm{z}_{0} \overrightarrow{\mathrm{k}}
$$

where $\vec{i}, \vec{j}$, and $\vec{k}$ are unit vectors along $X, Y, Z$.

Since the body $X, Y, Z$ axes are not constrained to be principal axes, the complete moment of inertia tensor

$$
\overline{\bar{I}} \equiv\left(\begin{array}{ccc}
I_{x x} & -I_{x y} & -I_{x z} \\
-I_{y x} & I_{y y} & -I_{y z} \\
-I_{z x} & -I_{z y} & I_{z z}
\end{array}\right)
$$

has been introduced.

Equations (6) and (7) are displayed in scalar form, in body axes, as follows:

$$
\begin{aligned}
& F_{X}=m\left[\dot{u}+w q-v r-x_{0}\left(q^{2}+r^{2}\right)+y_{0}(q p-\dot{r})+z_{0}(p r+\dot{q})\right] \\
& F_{Y}=m\left[\dot{v}+u r-w p+x_{0}(p q+\dot{r})-y_{0}\left(r^{2}+p^{2}\right)+z_{0}(r q-\dot{p})\right] \\
& F_{Z}=m\left[\dot{w}+v p-u q+x_{0}(p r-\dot{q})+y_{0}(q r+\dot{p})-z_{0}\left(p^{2}+q^{2}\right)\right]
\end{aligned}
$$

for the forces, and 


$$
\begin{aligned}
L= & \dot{p} I_{X X}-\dot{q} I_{X Y}-\dot{r} I_{X Z}-q\left(I_{Z X} p+I_{Z Y} q-I_{Z Z} r\right) \\
& +r\left(I_{Y X} p-I_{Y Y} q+I_{Y Z} r\right)+m_{0}[\dot{w}+v p-u q]-m z_{0}[\dot{v}+u r-w p] \\
M= & \dot{q} I_{Y Y}-\dot{r} I_{Y Z}-\dot{p} I_{Y X}-r\left(I_{X Y} q+I_{X Z} r-I_{X X} p\right) \\
& +p\left(I_{Z Y} q-I_{Z Z} r+I_{Z X} p\right)-m x_{0}[\dot{w}+v p-u q]+m z_{0}[\dot{u}+w q-v r] \\
N= & \dot{r} I_{Z Z}-\dot{p} I_{Z X}-\dot{q} I_{Z Y}-p\left(I_{Y Z} r+I_{Y X} p-I_{Y Y} q\right) \\
& +q\left(L_{X Z} r-I_{X X} p+I_{X Y} q\right)+m x_{0}[\dot{v}+u r-w p]-m_{0}[\dot{u}+w q-v r]
\end{aligned}
$$

for the moments.

These six equations may be arranged in the following matrix form

$$
\left(\begin{array}{cccccc}
\mathrm{m} & 0 & 0 & 0 & \mathrm{mz}_{0} & -\mathrm{my}_{0} \\
0 & \mathrm{~m} & 0 & -\mathrm{mz}_{0} & 0 & \mathrm{mx}_{0} \\
0 & 0 & \mathrm{~m} & \mathrm{my}_{0} & -\mathrm{mx}_{0} & 0 \\
0 & -\mathrm{mz}_{0} & \mathrm{my}_{0} & \mathrm{I}_{\mathrm{XX}} & -\mathrm{I}_{\mathrm{XY}} & -\mathrm{I}_{\mathrm{XZ}} \\
\mathrm{mz}_{0} & 0 & -\mathrm{mx}_{0} & -\mathrm{I}_{\mathrm{YX}} & \mathrm{I}_{\mathrm{YY}} & -\mathrm{I}_{\mathrm{Y} Z} \\
-\mathrm{my}_{0} & \mathrm{mx}_{0} & 0 & -\mathrm{I}_{\mathrm{ZX}} & -\mathrm{I}_{\mathrm{ZY}} & \mathrm{I}_{\mathrm{ZZ}}
\end{array}\right)\left(\begin{array}{c}
\dot{\mathrm{u}} \\
\dot{\mathrm{v}} \\
\dot{\mathrm{w}} \\
\dot{\mathrm{p}} \\
\dot{\mathrm{q}} \\
\dot{\mathrm{r}}
\end{array}\right)=\left(\begin{array}{c}
\mathrm{x}_{\mathrm{B}} \\
\mathrm{Y}_{\mathrm{B}} \\
\mathrm{ZB} \\
\mathrm{L}_{\mathrm{B}} \\
\mathrm{M}_{\mathrm{B}} \\
\mathrm{N}_{\mathrm{B}}
\end{array}\right)
$$

or

$$
B\left(\begin{array}{c}
\dot{u} \\
\dot{v} \\
\dot{w} \\
\dot{p} \\
\dot{q} \\
\dot{r}
\end{array}\right)=\left(\begin{array}{c}
\mathrm{x}_{\mathrm{B}} \\
\mathrm{Y}_{\mathrm{B}} \\
\mathrm{Z}_{\mathrm{B}} \\
\mathrm{L}_{\mathrm{B}} \\
\mathrm{M}_{\mathrm{B}} \\
\mathrm{N}_{\mathrm{B}}
\end{array}\right)
$$


The solution to this system is given by

$$
\left(\begin{array}{c}
\dot{u} \\
\dot{v} \\
\dot{w} \\
\dot{p} \\
\dot{q} \\
\dot{r}
\end{array}\right)=B^{-1}\left(\begin{array}{c}
x_{B} \\
Y_{B} \\
Z_{B} \\
{ }_{B} \\
{ }_{B} \\
{ }_{B} \\
N_{B}
\end{array}\right)
$$

In these equations the following definitions have been employed

$$
\begin{aligned}
& \left(\begin{array}{c}
X_{B} \\
Y_{B} \\
Z_{B}
\end{array}\right)=\left(\begin{array}{c}
F_{X} \\
F_{Y} \\
F_{Z}
\end{array}\right)-m\left(\begin{array}{l}
w q-v r-x_{0}\left(q^{2}+r^{2}\right)+y_{0} q p+z_{0} p r \\
u r-w p-y_{0}\left(r^{2}+p^{2}\right)+x_{0} p q+z_{0} r q \\
v p-u q-z_{0}\left(p^{2}+q^{2}\right)+x_{0} p r+y_{0} q r
\end{array}\right) \\
& \left(\begin{array}{l}
F_{X} \\
F_{Y} \\
F_{Z}
\end{array}\right)=\left(\begin{array}{l}
F_{X} \\
F_{Y} \\
F_{Z}
\end{array}\right)-\left(\begin{array}{l}
F_{X G} \\
F_{Y G} \\
F_{Z G}
\end{array}\right)
\end{aligned}
$$

and

$$
\left(\begin{array}{l}
F_{X} \\
F_{Y} \\
F_{Z}
\end{array}\right)_{\text {Aero }}=Q S\left(\begin{array}{l}
C_{X} \\
C_{Y} \\
C_{Z}
\end{array}\right)
$$

$$
\left(\begin{array}{l}
F_{X G} \\
F_{Y G} \\
F_{Z G}
\end{array}\right)=m g\left(\begin{array}{l}
{ }^{{ }^{X Y}} \\
{ }^{A_{Y Y}} \\
A_{Z Y}
\end{array}\right)
$$


in which $g$ is the acceleration of gravity and the second term in Equation (16) is simply the projection of $\mathrm{g}$ on $\mathrm{X}, \mathrm{Y}, \mathrm{Z}$ while $\mathrm{C}_{\mathrm{X}}, \mathrm{C}_{\mathrm{Y}}$, and $\mathrm{C}_{Z}$ are the aerodynamic force coefficients along $X, Y, Z$ respectively.

Also, in Equation (12)

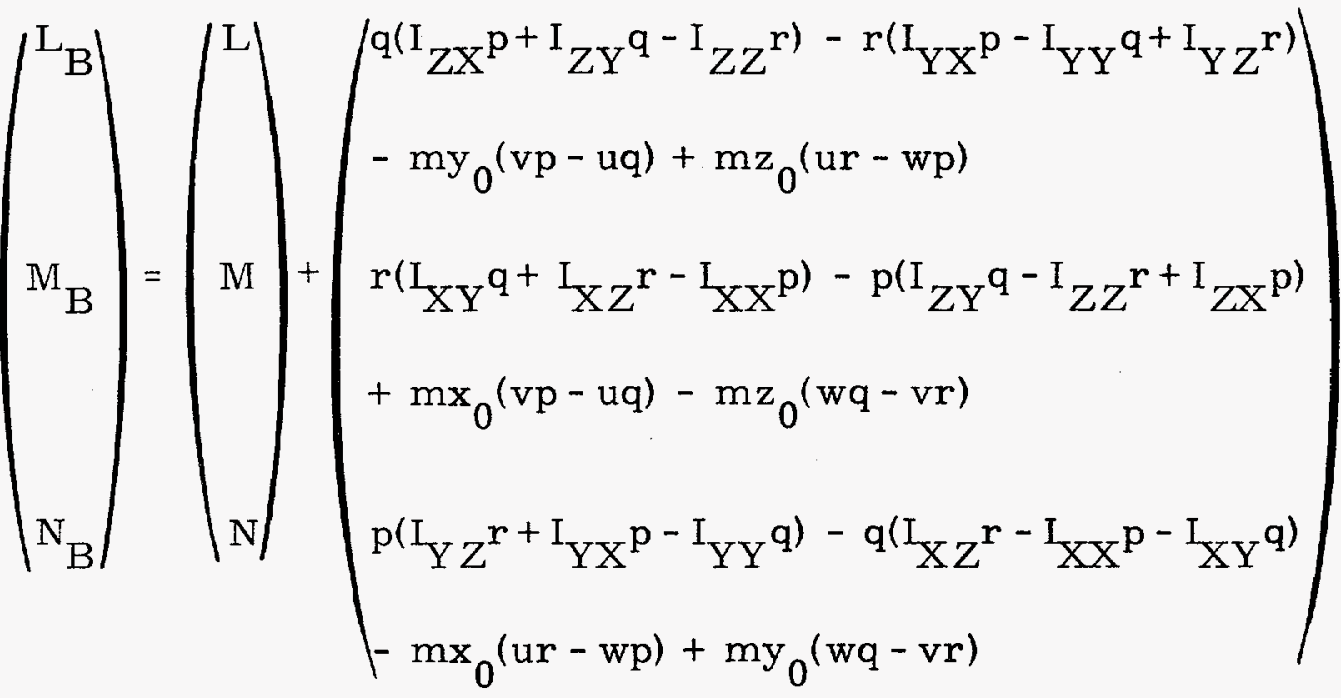

$$
\begin{aligned}
& \left(\begin{array}{l}
L \\
M \\
N
\end{array}\right)=\left(\begin{array}{l}
L \\
M \\
N
\end{array}\right)_{\text {Aero }}+\left(\begin{array}{l}
z_{0} F_{X G}-y_{0} F_{Z G} \\
x_{0} F_{Z G}-z_{0} F_{X G} \\
y_{0} F_{X G}-x_{0} F_{Y G}
\end{array}\right)
\end{aligned}
$$

and

$$
\left(\begin{array}{l}
L \\
M \\
N
\end{array}\right)_{\text {Aero }}=\operatorname{QSd}\left(\begin{array}{l}
C_{1} \\
C_{m} \\
C_{n}
\end{array}\right)
$$

where $\mathrm{C}_{1}, \mathrm{C}_{\mathrm{m}}$, and $\mathrm{C}_{\mathrm{n}}$ are the aerodynamic moment coefficients along $\mathrm{X}, \mathrm{Y}, \mathrm{Z}$ respectively. 
The translational motion relative to the inertial system is expressed

$$
\left(\begin{array}{l}
\dot{x} \\
\dot{y} \\
\dot{z}
\end{array}\right)=A^{-1}\left(\begin{array}{l}
u \\
v \\
w
\end{array}\right)
$$

Since the matrix A is orthogonal, its inverse is its transpose; consequently,

$$
\left(\begin{array}{c}
\dot{x} \\
\dot{y} \\
\dot{z}
\end{array}\right)=A^{T}\left(\begin{array}{l}
u \\
v \\
w
\end{array}\right)=\left(\begin{array}{lll}
A_{X X} & A_{Y X} & A_{Z X} \\
A_{X Y} & A_{Y Y} & A_{Z Y} \\
A_{X Z} & A_{Y Z} & A_{Z Z}
\end{array}\right)\left(\begin{array}{l}
u \\
v \\
w
\end{array}\right)
$$

In addition, the derivatives of the versor elements are determined from

$$
\left(\begin{array}{l}
\dot{\lambda}_{0} \\
\dot{\lambda}_{1} \\
\dot{\lambda}_{2} \\
\dot{\lambda}_{3}
\end{array}\right)=-1 / 2\left(\begin{array}{cccc}
o & p & q & r \\
-p & o & -r & q \\
-q & r & o & -p \\
-r & -q & p & q
\end{array}\right)\left(\begin{array}{c}
\lambda_{0} \\
\lambda_{1} \\
\lambda_{2} \\
\lambda_{3}
\end{array}\right)
$$

with the following normalization:

$$
\lambda_{0}^{2}+\lambda_{1}^{2}+\lambda_{2}^{2}+\lambda_{3}^{2}=1
$$

The aerodynamic force and moment coefficients in the previous equations will be developed in detail in a later section. 
The Differential Equations of Control Mass Motion

A conceptual spin-fin roll-control system is shown in Figure 4. This system was first developed by D. H. Platus ${ }^{12}$ of the Aerospace Corporation, and several mechanisms which are similar in concept have been designed at SLL. ${ }^{13}$ The system is designed to provide roll control to an RV by means of external, aerodynamic control surfaces. The variable-cant fins deflect due to the positions of internal proof masses (control masses). A linkage is adopted to convert the linear control mass motion (as determined by the total mass accelerations) to rotational fin motion.

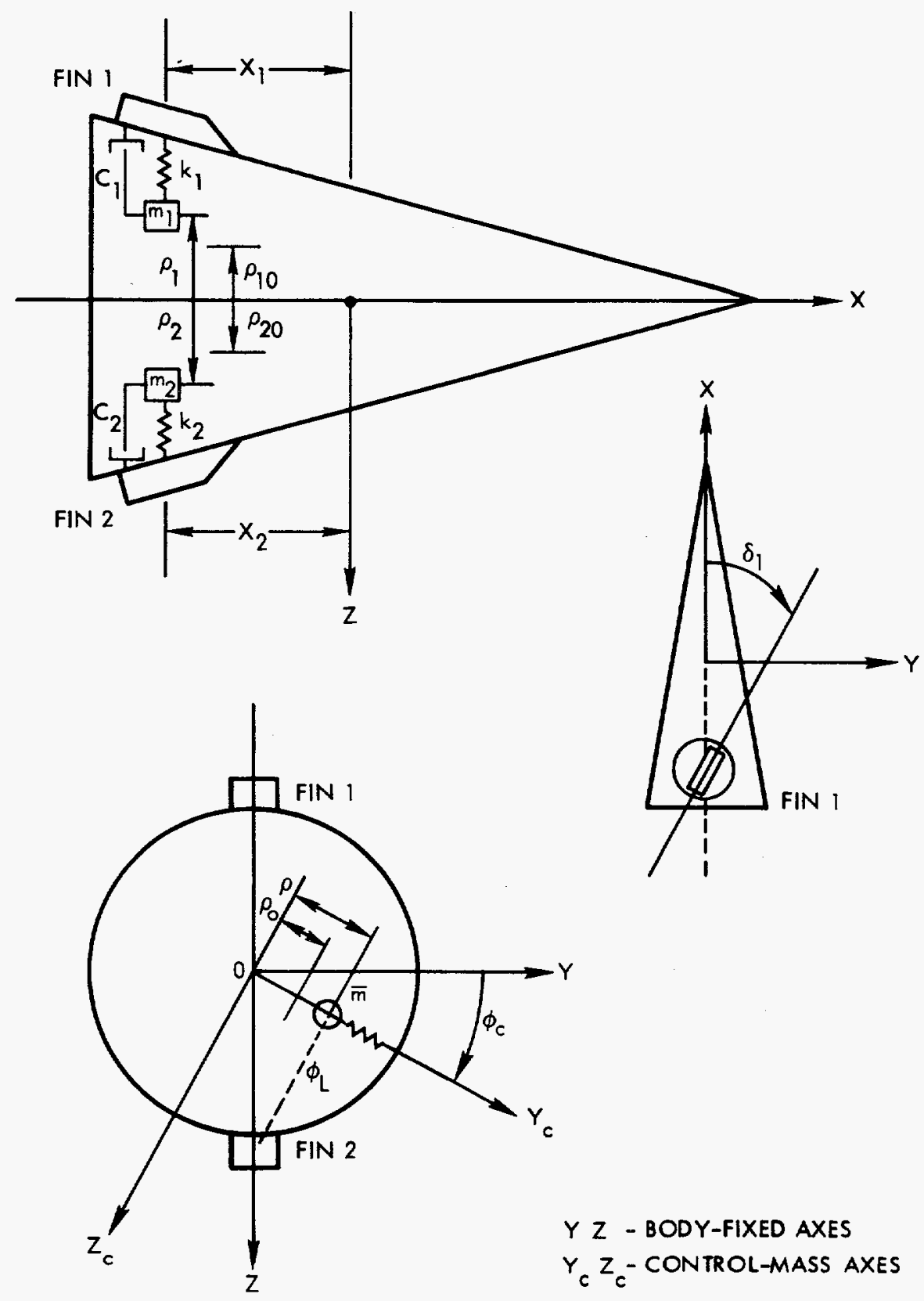

Figure 4. Conceptual SPINFIN Roll-Control System 
The total acceleration on the internal control masses is found by rederiving Equation (6) with the position, $R_{m}$, of the mass in the body system allowed to vary. The equation governing the internal mass motion is determined as

$$
\overrightarrow{\mathrm{F}}_{\mathrm{m}}=\overline{\mathrm{m}}\left[\dot{\overrightarrow{\mathrm{V}}}+\vec{\Omega} \times \overrightarrow{\mathrm{V}}+\dot{\vec{\Omega}} \times \overrightarrow{\mathrm{R}}_{\mathrm{m}}+\ddot{\overrightarrow{\mathrm{R}}}_{\mathrm{m}}+2 \vec{\Omega}_{\mathrm{s}} \dot{\overrightarrow{\mathrm{R}}}_{\mathrm{m}}\right]
$$

where $\vec{F}_{m}$ is the total force acting on the control mass and $\overline{\mathrm{m}}$ is the mass. The terms $\dot{\vec{R}}_{m}, \ddot{\vec{R}}_{m}$ are the velocity and acceleration respectively of the internal mass relative to the body axes.

At this point, it is worthwhile to introduce an alternate coordinate system (designated the control-mass coordinate system) to facilitate the development of the control-mass equations of motion. It is generally the case (for SLL control systems ${ }^{3}, 4,13$ ) that the control mass is constrained to have motion along a line. However, this line may have an arbitrary angular orientation relative to the body. The control mass will be constrained to have motion along one axis of the control mass system, and thus only one scalar component of Equation (26) is necessary providing the variables are rotated into the new frame. The control mass system is shown in Figure 5. The origin, $O_{c}$, coincides with the origin of the body fixed axis. The orientation of $X_{C}, Y_{C}, Z_{c}$ relative to $X, Y, Z$ is determined

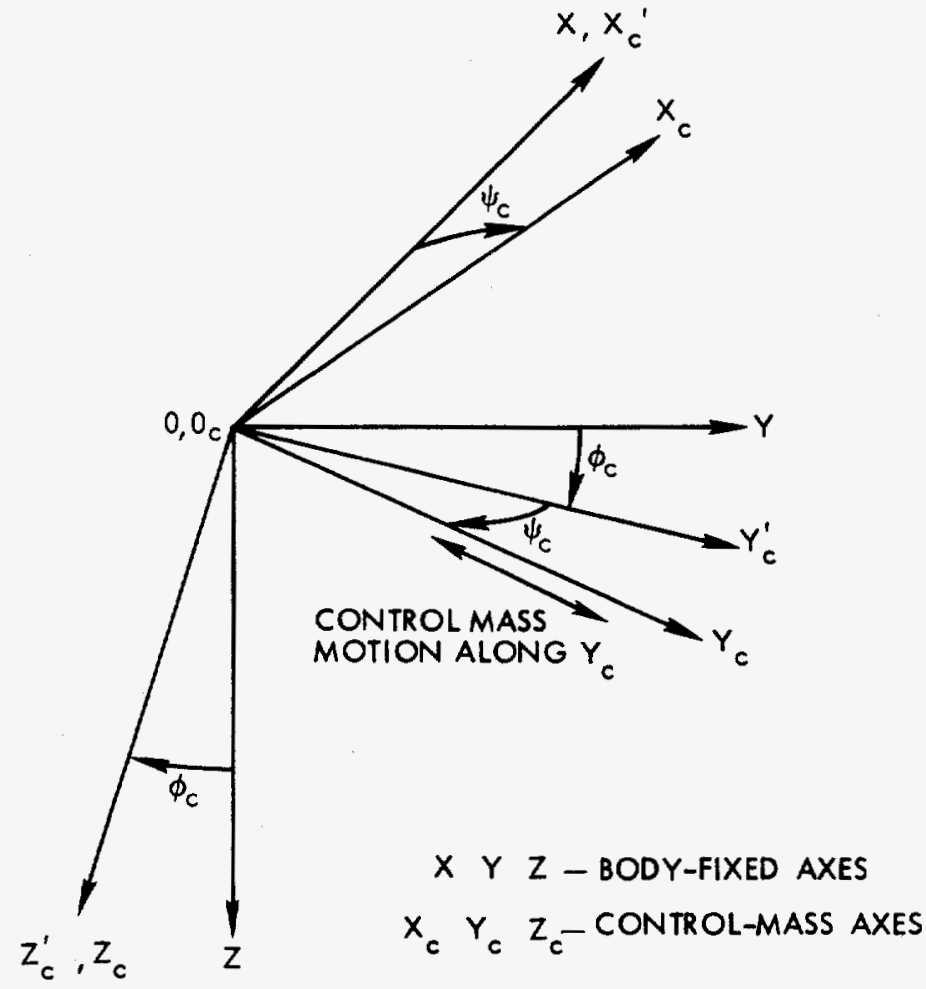

Figure 5. Body-Fixed Axes and Control-Mass Axes 
by the two ordered rotations $\phi_{c}$ and $\psi_{c}$ as shown. The control mass is constrained to move along $Y_{c}$ in this new system. The transformation matrix relating a vector $(X, Y, Z)$ in the body axes to a vector $\left(X_{c}, Y_{c}, Z_{c}\right)$
in the control system axes is given as

$$
\left(\begin{array}{c}
X_{c} \\
Y_{c} \\
Z_{c}
\end{array}\right)=\left(\begin{array}{ccc}
\cos \psi_{c} & \sin \psi_{c} \cos \phi_{c} & \sin \psi_{c} \sin \phi_{c} \\
-\sin \psi_{c} & \cos \psi_{c} \cos \phi_{c} & \cos \psi_{c} \sin \phi_{c} \\
0 & -\sin \phi_{c} & \cos \phi_{c}
\end{array}\right)\left(\begin{array}{l}
X \\
Y \\
z
\end{array}\right)=C\left(\begin{array}{l}
X \\
Y \\
Z
\end{array}\right)
$$

The matrix $\mathrm{C}$ is noted to be orthogonal; therefore

$$
\left(\begin{array}{l}
X \\
Y \\
Z
\end{array}\right)=C^{-1}\left(\begin{array}{c}
X_{c} \\
Y_{c} \\
Z_{c}
\end{array}\right)=C^{T}\left(\begin{array}{c}
X_{c} \\
Y_{c} \\
Z_{c}
\end{array}\right)
$$

Equation (26) is now expressed in the $\mathrm{X}_{\mathrm{c}}, \mathrm{Y}_{c}, \mathrm{Z}_{\mathrm{c}}$ system by a transformation of each variable in accordance with ${ }^{c}$ Equation ${ }^{c}(27)$. Since the motion of the mass is constrained to be along $\mathrm{Y}_{\mathrm{c}}$, we are only interested in that component of Equation (26) which is written

$$
\begin{aligned}
F_{m_{c}}=\bar{m} a_{m y_{c}}= & \bar{m}\left[\dot{v}_{c}+u_{c} r_{c}-w_{c} p_{c}+x_{m_{c}}\left(p_{c} q_{c}+\dot{r}_{c}\right)-y_{m_{c}}\left(r_{c}^{2}+p_{c}^{2}\right)\right. \\
& \left.+z_{m_{c}}\left(r_{c} q_{c}-\dot{p}_{c}\right)+\ddot{y}_{m_{c}}\right]
\end{aligned}
$$

where the mass position has been designated

and

$$
\begin{aligned}
& \overrightarrow{\mathrm{R}}_{\mathrm{m}_{c}}=\mathrm{x}_{\mathrm{m}_{c}} \overrightarrow{\mathrm{i}}_{\mathrm{c}}+\mathrm{y}_{\mathrm{m}_{\mathrm{c}}} \overrightarrow{\mathrm{j}}_{\mathrm{c}}+\mathrm{z}_{\mathrm{m}_{c}} \overrightarrow{\mathrm{k}}_{\mathrm{c}} \\
& \dot{\overrightarrow{\mathrm{R}}}_{\mathrm{m}_{\mathrm{c}}}=\dot{\mathrm{y}}_{\mathrm{m}_{\mathrm{c}}} \overrightarrow{\mathrm{j}}_{\mathrm{c}}, \quad \ddot{\vec{R}}_{\mathrm{m}_{c}}=\ddot{\mathrm{y}}_{\mathrm{m}_{\mathrm{c}}} \overrightarrow{\mathrm{j}}_{\mathrm{c}}
\end{aligned}
$$

with $\vec{i}_{c}, \vec{j}_{c}, \vec{k}_{c}$ being unit vectors along $X_{c}, Y_{c}, Z_{c}$ respectively. 
The linear and angular velocities and accelerations appearing in Equation (29) are expressed in the $X_{c}, Y_{c}, Z_{c}$ system.

The total force acting on the mass consists of spring restoring, spring damping, aerodynamic, and frictional terms and is expressed as

$$
\mathrm{F}_{\mathrm{m}_{\mathrm{C}}}=-\mathrm{k}\left(\mathrm{y}_{\mathrm{m}_{\mathrm{c}}}-\mathrm{y}_{\mathrm{c}_{0}}\right)-\mathrm{c}_{\mathrm{m}_{\mathrm{c}}}+\mathrm{F}_{\mathrm{m}_{\text {Aero }}}-\mathrm{f}_{\mathrm{m}}
$$

in which the first two terms are the spring restoring and damping forces respectively. The relaxed spring position is designated $\mathrm{y}_{\mathrm{c}_{0}}$.

$\mathrm{F}_{\mathrm{mero}}$ is a force applied to the mass through the linkage due to an aerodynamic torque acting on the fin. This torque is generated by the fin aerodynamic center-of-pressure being non-coincident with the fin hinge line. The frictional force, $\mathrm{f}_{\mathrm{m}}$, is considered as being composed of a constant term, and terms proportional to fin aerodynamic loading and vehicle axial acceleration. These terms will be described in the next section.

The geometric fin-cant angle, $\delta$, is formed from the control-mass position, $\mathrm{y}_{\mathrm{m}_{\mathrm{c}}}$. The control designs have used linear variations given by

$$
\delta=\delta_{0}-\phi_{L}\left(\mathrm{y}_{\mathrm{m}_{\mathrm{c}}}-\mathrm{y}_{\mathrm{c}_{\mathrm{I}}}\right)
$$

where $\phi_{L}$ will be referred to as the linkage constant which is written

$$
\phi_{L}=\left(\frac{\delta_{0}-\delta_{\min }}{{ }_{c_{\max }-y_{c_{I}}}}\right)
$$

The fin-cant/mass-position relationship as well as a description of the quantities in Equations (31) and (32) are presented in Figure 6. 


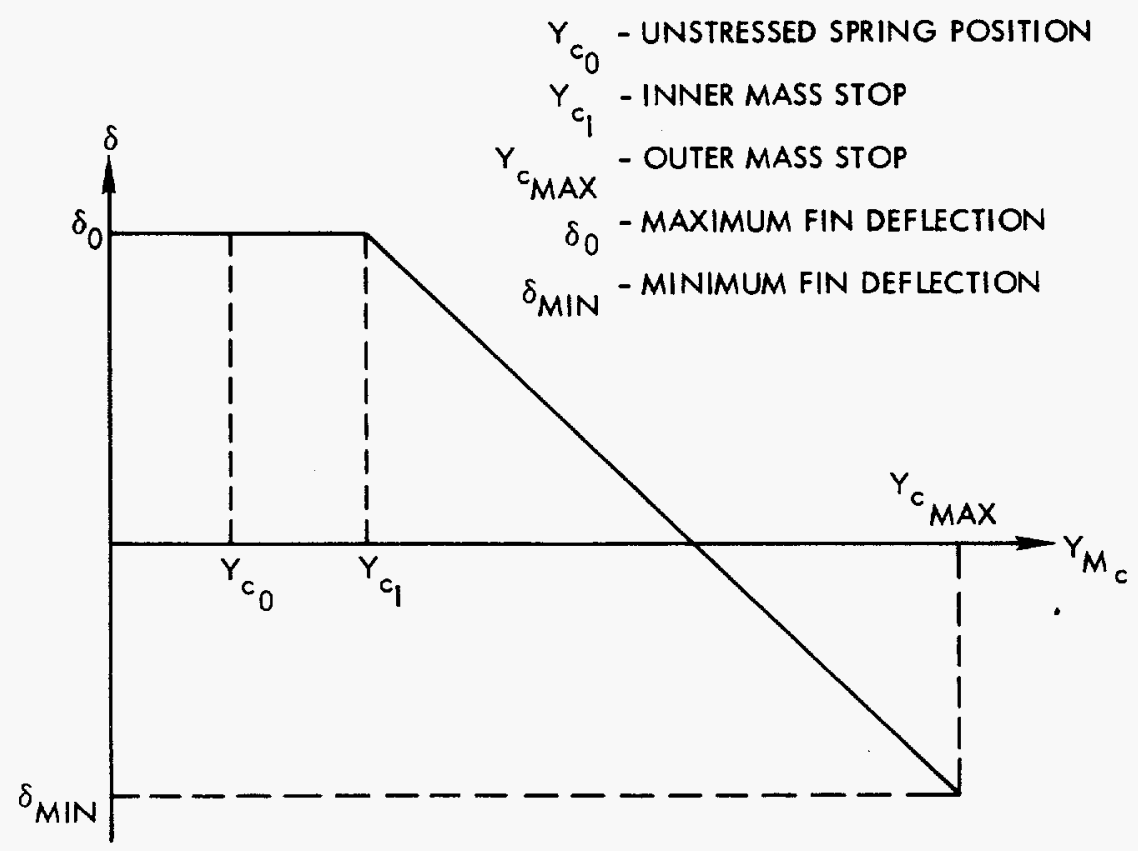

Figure 6. Representation of Geometric Fin Deflection versus Control-Mass Position

The equations of motion for independently actuated fins as well as coupled fin systems will now be presented.

$\mathrm{y}_{\mathrm{m}_{\mathrm{c}}}$ by $\rho$, the differential equation of motion for each control mass is obtained as:

$$
\begin{aligned}
\ddot{p}_{1}= & \frac{1}{\bar{m}_{1}}\left[-k_{1}\left(\rho_{1}-p_{1}\right)-c_{1} \dot{p}_{1}+F_{1}{ }_{\text {Aero }}-f_{1}\right] \\
& -\left(\dot{v}_{1}+u_{1} r_{1}-w_{1} p_{1}\right)-x_{m_{1}}\left(p_{1} q_{1}+\dot{r}_{1}\right) \\
& -z_{m_{1}}\left(r_{1} q_{1}-\dot{p}_{1}\right)+\rho_{1}\left(r_{1}^{2}+p_{1}^{2}\right)
\end{aligned}
$$

for mass 1 , and 


$$
\begin{aligned}
\ddot{\rho}_{2}= & \frac{1}{\overrightarrow{\mathrm{m}}_{2}}\left[-\mathrm{k}_{2}\left(\rho_{2}-\rho_{2}\right)-c_{2} \dot{p}_{2}+\mathrm{F}_{2} \text { Aero }-\mathrm{f}_{2}\right] \\
& -\left(\dot{v}_{2}+\mathrm{u}_{2} \mathrm{r}_{2}-\mathrm{w}_{2} \mathrm{p}_{2}\right)-\mathrm{x}_{\mathrm{m}_{2}}\left(\mathrm{p}_{2} \mathrm{q}_{2}+\mathrm{r}_{2}\right) \\
& -\mathrm{z}_{\mathrm{m}_{2}}\left(\mathrm{r}_{2} \mathrm{q}_{2}-\dot{\mathrm{p}}_{2}\right)+\rho_{2}\left(\mathrm{r}_{2}^{2}+\mathrm{p}_{2}^{2}\right)
\end{aligned}
$$

for mass 2 .

The extension to account for any number of control masses is obvious. In the se equations, the friction force, $f_{i}$, is expressed

$$
\mathrm{f}_{1,2}=\left(\overrightarrow{\mathrm{f}}+\vec{\mu} \mathrm{F}_{\text {Fin }_{1,2}}+\hat{\mu} \mathrm{x}_{\mathrm{F}}\right) \operatorname{Sign}\left(\dot{\rho}_{1,2}\right)
$$

where the latter two terms have been introduced to allow trajectory dependence in mechanism friction. In Equation (35), the following identities are employed

$$
\begin{aligned}
& \overline{\mathrm{f}}=\text { a constant control mechanism friction force (lb) } \\
& \text { for a } 1-\mathrm{g} \text { environment } \\
& \bar{\mu}=\text { friction force proportionality constant relating the } \\
& \mathrm{F}_{\text {Fin }_{1,2}}=\mathrm{C}_{\mathrm{F}_{1,2}} \mathrm{QS}=\text { total fin aerodynamic force acting on } \\
& \text { fins } 1 \text { and } 2 \text { respectively (lb) } \\
& \mathrm{C}_{\mathrm{F}_{1,2}}=\sqrt{\mathrm{C}_{\mathrm{A}_{1,2}^{2}}^{2}+\mathrm{C}_{\mathrm{N}_{\mathrm{F}}}^{2}}=\begin{array}{l}
\text { total fin aerodynamic force } \\
\text { coefficients for fins } 1 \text { and } 2 \\
\text { respectively (see aerodynamics } \\
\text { section) }
\end{array} \\
& \hat{\mu}=\text { friction force proportionality constant relating total } \\
& \text { vehicle axial acceleration (in } g^{\prime} s \text { ) to mechanism } \\
& \text { friction force } \\
& X_{F}=\text { magnitude of vehicle axial acceleration (in } g^{\prime} s \text { ) } \\
& \text { Sign }\left(\dot{\rho}_{1,2}\right)\left\{\begin{array}{cc}
-1 & \text { for } \dot{\rho}_{1,2}<0 \\
0 & \text { for } \dot{p}_{1,2}=0 \\
+1 & \text { for } \dot{\rho}_{1,2}>0
\end{array}\right.
\end{aligned}
$$

and 
The force on the mass produced by an aerodynamic torque acting on the fin due to the fin center-of-pressure being non-coincident with the hinge line is given by

$$
\mathrm{F}_{1,2}=\mathrm{C}_{\mathrm{N}_{\text {Aero }}}{ }_{1,2}{ }_{1,2} \mathrm{QS} \phi_{\mathrm{L}_{1,2}}
$$

in which

$$
\begin{aligned}
\mathrm{C}_{\mathrm{N}_{\mathrm{F}_{1,2}}}= & \text { fin normal force coefficient on fins } 1 \text { and } 2 \text { respectively } \\
{ }_{1,2}= & \begin{array}{l}
\text { distance in feet along fin chord from fin hinge line to } \\
\quad \text { fin center-of-pressure for fins } 1 \text { and } 2 \text { respectively }
\end{array} \\
\quad \text { (positive when center-of-pressure is aft of hinge line) } & \text { fin-mass linkage constant for fins } 1 \text { and } 2 \text { respectively }
\end{aligned}
$$

After Equations (33) and (34) are solved for $\rho_{1,2}$, the geometric fin cants (and aerodynamic forces and moments) may be determined from

$$
\delta_{1,2}=\delta_{0}{ }_{1,2}-\phi_{L_{1,2}}\left(\rho_{1,2}-\rho_{1,2}\right)
$$

where

$$
\phi_{\mathrm{L}_{1,2}}=\left(\frac{{ }_{0}^{\delta_{1,2}}-\delta_{\min }{ }_{1,2}}{\rho_{1,2}{ }_{\max }-\rho_{1,2_{I}}}\right)
$$

Note that the physical parameters for each system can be different.

The variables $u_{1,2}, p_{1,2}$, etc. used in Equations (33) and (34) are in the $X_{C}, Y_{c}, Z_{c}$ system and are obtained by a rotation of the $X, Y, Z$ variables as suggested by Equation (27). However, the orientation angles are permitted to be different for each system. Therefore,

$$
\left(\begin{array}{c}
X_{c} \\
Y_{c} \\
Z_{c}
\end{array}\right)_{1,2}=C_{1,2}\left(\begin{array}{l}
X \\
Y \\
Z
\end{array}\right)
$$


where the transformation matrix $\mathrm{C}_{i}$ is given by Equation (27). The orientation angles $\phi_{c_{1}}$ and $\psi_{c_{1}}$ of the axis of motion of control mass $\bar{m}_{1}$ are used to construct $\mathrm{C}_{1}$. Similarly, $\psi_{\mathrm{c}_{2}}$ and $\phi_{\mathrm{c}_{2}}$ which define the axis of $\overline{\mathrm{m}}_{2}$ motion are used to construct $\mathrm{C}_{2}$.

Coupled Fins - - Several mechanisms have been designed which insure equivalent motion and displacement of the control masses. Assuming no losses in the coupling mechanism, the control mass positions are given as*

$$
p_{1}=\rho_{2}=\rho
$$

and

$$
\begin{aligned}
& \dot{\rho}_{1}=\dot{\rho}_{2}=\dot{\rho} \\
& \ddot{\rho}_{1}=\ddot{\rho}_{2}=\ddot{\rho}
\end{aligned}
$$

These requirements are incorporated in Equations (33) and (34) which are then combined to yield a single differential equation for control-mass motion.

* It has been demonstrated that mechanisms can be and have been developed within this restriction. 


$$
\begin{aligned}
\ddot{p}= & -\frac{\left(\mathrm{k}_{1}+\mathrm{k}_{2}\right)}{\left(\overline{\mathrm{m}}_{1}+\overline{\mathrm{m}}_{2}\right)} \rho-\frac{\left(\mathrm{c}_{1}+\mathrm{c}_{2}\right)}{\left(\overline{\mathrm{m}}_{1}+\overline{\mathrm{m}}_{2}\right)} \dot{\rho}+\frac{\left(\mathrm{k}_{1} \rho_{1_{0}}+\mathrm{k}_{2} \rho_{2}\right)}{\left(\overline{\mathrm{m}}_{1}+\overline{\mathrm{m}}_{2}\right)} \\
& +\frac{\left(\mathrm{F}_{1}{ }_{\text {Aero }}+\mathrm{F}_{2}{ }_{\text {Aero }}\right)}{\left(\overline{\mathrm{m}}_{1}+\overline{\mathrm{m}}_{2}\right)}-\frac{\left(\mathrm{f}_{1}+\mathrm{f}_{2}\right)}{\left(\overline{\mathrm{m}}_{1}+\overline{\mathrm{m}}_{2}\right)}+\rho \frac{\left[\overline{\mathrm{m}}_{1}\left(\mathrm{r}_{1}{ }^{2}+\mathrm{p}_{1}\right)+\overline{\mathrm{m}}_{2}\left(\mathrm{r}_{2}^{2}+\mathrm{p}_{2}\right)\right]}{\left(\overline{\mathrm{m}}_{1}+\overline{\mathrm{m}}_{2}\right)} \\
& -\frac{\left[\overline{\mathrm{m}}_{1}\left(\dot{\mathrm{v}}_{1}+\mathrm{u}_{1} \mathrm{r}_{1}-\mathrm{w}_{1} \mathrm{p}_{1}\right)+\overline{\mathrm{m}}_{2}\left(\dot{\mathrm{v}}_{2}+\mathrm{u}_{2} \mathrm{r}_{2}-\mathrm{w}_{2} \mathrm{p}_{2}\right)\right]}{\left(\overline{\mathrm{m}}_{1}+\overline{\mathrm{m}}_{2}\right)} \\
& -\frac{\left[\overline{\mathrm{m}}_{1} \mathrm{x}_{\mathrm{m}_{1}}\left(\mathrm{p}_{1} \mathrm{q}_{1}+\dot{\mathrm{r}}_{1}\right)+\overline{\mathrm{m}}_{2} \mathrm{x}_{\mathrm{m}_{2}}\left(\mathrm{p}_{2} \mathrm{q}_{2}-\dot{\mathrm{r}}_{2}\right)\right]}{\left(\overline{\mathrm{m}}_{1}+\overline{\mathrm{m}}_{2}\right)} \\
& -\frac{\left[\overline{\mathrm{m}}_{1} \mathrm{z}_{\mathrm{m}_{1}}\left(\mathrm{r}_{1} \mathrm{q}_{1}-\dot{\mathrm{p}}_{1}\right)+\overline{\mathrm{m}}_{2} \mathrm{z}_{\mathrm{m}_{2}}\left(\mathrm{r}_{2} \mathrm{q}_{2}-\dot{\mathrm{p}}_{2}\right)\right]}{\left(\overline{\mathrm{m}}_{1}+\overline{\mathrm{m}}_{2}\right)}
\end{aligned}
$$

The expressions for friction and aerodynamic forces are as previously given in Equations (35), (36), (37), and (38), while Equations (39) and (40) are employed to determine the geometric fin cants once the mass positions have been obtained.

\section{Specification of Aerodynamics}

The description of aerodynamic characteristics presented herein is taken from the treatment given in References 1 and 11 . The vehicle aerodynamic coefficients are considered as nonlinear functions of the total angleof-attack, Mach number, roll orientation, and fin cant. In addition, each coefficient is allowed to vary with altitude to more closely simulate and model effects such as ablation, boundary-layer transition, etc. The roll orientation dependence is accounted for by decomposing the coefficients into contributions due to cross velocity and cross spin. This is accomplished by expanding the fin and/or body coefficients as truncated Fourier functions of the roll-orientation angle.

Two methods of specifying the aerodynamic characteristics of the flight vehicle are developed. In either case, the form of the coefficient expansions is sufficiently general to handle the most complex of vehicle shapes. The validity of such expressions has been verified both analytically and experimentally. The first method consists of expanding as functions 
of the roll angle the total body forces and moments (including fins) in component form along each of the body $\mathrm{X}, \mathrm{Y}, \mathrm{Z}$ axes. The second method consists of expanding individual fin forces alone as Fourier functions of the roll angle. These are then combined with the vehicle aerodynamic characteristics (which are determined separately) to form the total body forces and moments along the body $X, Y, Z$ axes. The former method is necessarily restricted to equal fin cants (coupled fins), while the latter method may be employed when specifying the aerodynamics for unequal cants and is the method generally employed.

Body Aerodynamics -- In this development, each of the total force and moment coefficients along the body $\mathrm{X}, \mathrm{Y}, \mathrm{Z}$ axes are expressed as functions of the angle-of-attack, Mach number, fin cant, and roll orientation. The latter dependence is accounted for by expanding each of these coefficients as truncated Fourier functions of the roll angle. This technique is necessarily restricted to the case of equal fin cants, and in the following equations, $\delta$ is taken to be the geometric fin cant of both spin fins.

To accomplish the derivation of the non-dimensional aerodynamic coefficients, two coordinate systems are introduced, as shown in Figures 7 and 8 , to denote the cross-velocity and cross-spin systems respectively.

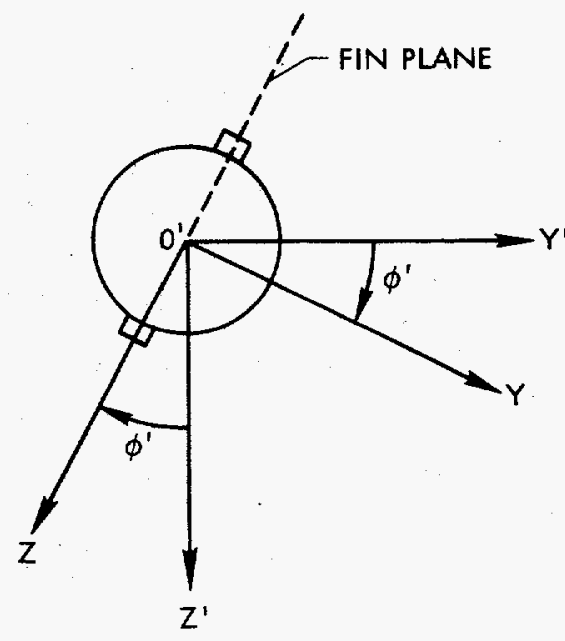

Figure 7. Cross-Velocity System

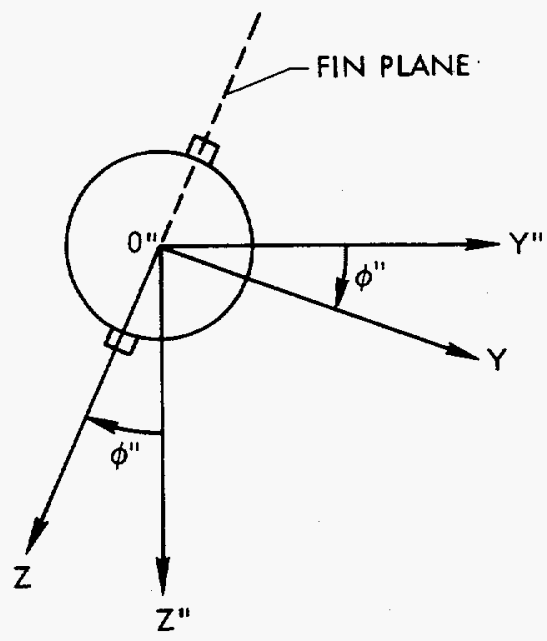

Figure 8. Cross-Spin System 
In each case, the primed coordinate reference frames are equivalent to wind tunnel pitch axes, while the non-primed systems are the body-fixed axes. The primed systems are those in which conventional wind tunnel aerodynamic data are obtained. The cross-velocity frame $O^{\prime}, X, Y^{\prime}, Z^{\prime}$ has $Z^{\prime}$ in the direction of cross-velocity $(0, v, w)$ while the cross-spin system $\mathrm{O}^{\prime \prime}, \mathrm{X}, \mathrm{Y}^{\prime \prime}, \mathrm{Z}^{\prime \prime}$ has $\mathrm{Y}^{\prime \prime}$ in the direction of cross-spin $(0, q, r)$ with the respective roll angles, $\phi^{\prime}$ and $\phi^{\prime \prime}$, as shown. Consequently, in Figure 7, the missile is viewed from the rear, and $Y^{\prime}, Z^{\prime}, \phi^{\prime}$, and $\alpha^{\prime}=\tan ^{-1}\left(\frac{\sqrt{v^{2}+w^{2}}}{u}\right)$ correspond to wind tunnel quantities in, for example, static force tests in which the angle of attack is positive (nose upward) and the roll angle is $\phi$. Similarly, in Figure 8, $Y^{\prime \prime}, Z^{\prime \prime}$, and $\phi^{\prime \prime}$ are wind tunnel quantities for a missile oscillating in pitch with roll angle $\phi$.

From arguments of symmetry, the coefficients of an n-finned missile must be periodic functions of $n \phi$, where $\phi$ is the roll angle. These are expanded as $\sin n m \phi$ and $\cos n m \phi$ with the series truncated at $m=1$. The validity of this trunction of the Fourier series has been verified both analytically 6,7 and experimentally ${ }^{8}$ for the case of a finned cone. Under these assumptions, the aerodynamic coefficients are expressed as follows:

$$
\begin{aligned}
& \mathrm{C}_{\mathrm{X}}\left(\alpha^{\prime}, \mathrm{M}, \phi, \delta\right)=\mathrm{C}_{\mathrm{X}}\left(\alpha^{\prime}, M, \delta\right) \\
& \mathrm{C}_{\mathrm{Y}^{\prime}}\left(\alpha^{\prime}, \mathrm{M}, \phi^{\prime}, \delta\right)=\mathrm{C}_{\mathrm{Y}^{\prime}{ }_{0}}\left(\alpha^{\prime}, \mathrm{M}, \delta\right)+\mathrm{C}_{\mathrm{Y}^{\prime}{ }_{1}}\left(\alpha^{\prime}, \mathrm{M}, \delta\right) \sin \mathrm{n} \phi^{\prime} \\
& +\mathrm{C}_{\mathrm{Y}^{\prime}{ }_{2}}\left(\alpha^{\prime}, \mathrm{M}, \delta\right) \cos \mathrm{n} \phi^{\prime}+\mathrm{C}_{\mathrm{Y}^{\prime}}\left(\alpha_{\mathrm{p}}^{\prime}, \mathrm{M}, \delta\right) \mathrm{pd} / 2 \mathrm{~V} \\
& C_{Z^{\prime}}\left(\alpha^{\prime}, M, \phi^{\prime}, \delta\right)=C_{Z^{\prime}}\left(\alpha^{\prime}, M, \delta\right)+C_{Z^{\prime}}\left(\alpha^{\prime}, M, \delta\right) \sin n \phi^{\prime} \\
& +\mathrm{C}_{Z_{2}^{\prime}}\left(\alpha^{\prime}, \mathrm{M}, \delta\right) \cos \mathrm{n} \phi^{\prime} \\
& C_{1}\left(\alpha^{\prime}, M, \phi^{\prime}, p, \delta\right)=C_{1_{0}}\left(\alpha^{\prime}, M, \delta\right)+C_{1_{\delta}}\left(\alpha^{\prime}, M ! \delta\right)+C_{1_{p}}\left(\alpha^{\prime}, M, \delta\right) p d / 2 V \\
& +C_{1}\left(\alpha^{\prime}, M ! \delta\right) \sin n \phi^{\prime}+C_{1_{2}}\left(\alpha^{\prime}, M, \delta\right) \cos n \phi^{\prime}
\end{aligned}
$$




$$
\begin{aligned}
& \mathrm{C}_{\mathrm{m}^{\prime}}\left(\alpha^{\prime}, \mathrm{M}, \phi^{\prime}, \delta\right)=\mathrm{C}_{\mathrm{m}^{\prime}{ }_{0}}\left(\alpha^{\prime}, \mathrm{M}, \delta\right)+\mathrm{C}_{\mathrm{m}^{\prime}{ }_{1}}\left(\alpha^{\prime}, \mathrm{M}, \delta\right) \sin \mathrm{n} \phi^{\prime}+\mathrm{C}_{\mathrm{m}^{\prime}{ }_{2}}\left(\alpha^{\prime}, \mathrm{M}, \delta\right) \cos \mathrm{n} \phi^{\prime} \\
& +\left[\mathrm{C}_{\mathrm{m}^{\prime \prime} \mathrm{q}^{\prime \prime}{ }_{0}\left(\alpha^{\prime}, \mathrm{M}, \delta\right)+\mathrm{C}_{\mathrm{m}^{\prime \prime} \mathrm{q}^{\prime \prime}{ }_{1}}\left(\alpha^{\prime}, \mathrm{M}, \delta\right) \sin \mathrm{n} \phi^{\prime \prime}}\right.
\end{aligned}
$$

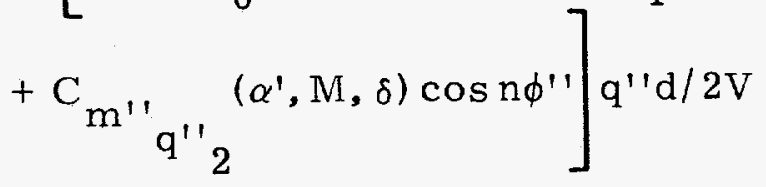

$$
\begin{aligned}
& C_{n^{\prime}}\left(\alpha^{\prime}, M, \phi^{\prime}, \delta\right)=C_{n^{\prime}{ }_{0}}\left(\alpha^{\prime}, M, \delta\right)+C_{n^{\prime}{ }_{1}}\left(\alpha^{\prime}, M, \delta\right) \sin n \phi^{\prime} \\
& +\mathrm{C}_{\mathrm{n}^{\prime}}\left(\alpha^{\prime}, M, \delta\right) \cos \mathrm{n} \phi^{\prime}+\mathrm{C}_{\mathrm{n}^{\prime}}\left(\alpha_{\mathrm{p}}, \mathrm{M}, \delta\right) \mathrm{pd} / 2 \mathrm{~V}
\end{aligned}
$$

with $\mathrm{n}=2$ for the spin-fin system. The extension of the foregoing to any number of fins is evident. The total coefficients in the body axes are then written

$$
\begin{aligned}
& \mathrm{C}_{\mathrm{X}}=\mathrm{C}_{\mathrm{X}} \\
& C_{Y}=\left\{C_{Y^{\prime}{ }_{0}}+C_{Y^{\prime}{ }_{1}} \sin n \phi^{\prime}+C_{Y^{\prime}{ }_{2}} \cos n \phi^{\prime}+C_{Y^{\prime}} \operatorname{pd} / 2 V \mid \cos \phi^{\prime}\right. \\
& \left\{\mathrm{C}_{\mathrm{Z}^{\prime}{ }_{0}}+\mathrm{C}_{\mathrm{Z}^{\prime}{ }_{1}} \sin n \phi^{\prime}+\mathrm{C}_{\mathrm{Z}^{\prime}{ }_{2}} \cos n \phi^{\prime}\right\} \sin \phi^{\prime}+\mathrm{C}_{\mathrm{Y}} \\
& C_{Z}=-\left\{C_{Y^{\prime}{ }_{0}}+C_{Y^{\prime}{ }_{1}} \sin n \phi^{\prime}+C_{Y^{\prime}{ }_{2}} \cos n \phi^{\prime}+C_{Y^{\prime}} \operatorname{pd} / 2 V\right\} \sin \phi^{\prime} \\
& +\left\{C_{Z_{0}^{\prime}}+C_{Z^{\prime}{ }_{1}} \sin n \phi^{\prime}+C_{Z^{\prime}} \cos n \phi^{\prime}\right\} \cos \phi^{\prime}+C_{Z_{\epsilon}} \\
& C_{1}=C_{1_{0}}+C_{1_{\delta}}+C_{1_{p}} p d / 2 V+C_{1_{1}} \sin n \phi^{\prime}+C_{1_{2}} \cos n \phi^{\prime} \\
& \mathrm{C}_{\mathrm{m}}=\left\{\mathrm{C}_{\mathrm{m}^{\prime}{ }_{0}}+\mathrm{C}_{\mathrm{m}^{\prime}{ }_{1}} \sin \mathrm{n} \phi^{\prime}+\mathrm{C}_{\mathrm{m}^{\prime}{ }_{2}} \cos \mathrm{n} \phi^{\prime}\right\} \cos \phi^{\prime} \\
& +\left\{C_{m^{\prime \prime} q^{\prime \prime}{ }_{0}}+C_{m^{\prime \prime} q^{\prime \prime}{ }_{1}} \sin n \phi^{\prime \prime}+C_{m^{\prime \prime} q^{\prime \prime}{ }_{2}} \cos n \phi^{\prime \prime}\right\} \cos \phi^{\prime \prime} q^{\prime \prime} d / 2 V \\
& +\left\{C_{n_{0}^{\prime}}+C_{n^{\prime}{ }_{1}} \sin n \phi^{\prime}+C_{n^{\prime}{ }_{2}} \cos n \phi^{\prime}+C_{n^{\prime}{ }_{p}} p d / 2 V\right\} \sin \phi^{\prime}+C_{m_{\epsilon}}
\end{aligned}
$$




$$
\begin{aligned}
& \mathrm{C}_{\mathrm{n}}=-\left\{\mathrm{C}_{\mathrm{m}_{0}^{\prime}}+\mathrm{C}_{\mathrm{m}_{1}^{\prime}} \sin \mathrm{n}^{\prime}+\mathrm{C}_{\mathrm{m}_{2}^{\prime}} \cos \mathrm{n} \phi^{\prime}\right\} \sin \phi^{\prime} \\
& +\left\{C_{n^{\prime}}+C_{n^{\prime}{ }_{1}} \sin n \phi^{\prime}+C_{n^{\prime}{ }_{2}} \cos n \phi^{\prime}+C_{n^{\prime}} p d / 2 V\right\} \cos \phi^{\prime} \\
& -\left\{\mathrm{C}_{\mathrm{m}^{\prime \prime} \mathrm{q}^{\prime \prime}{ }_{0}}+\mathrm{C}_{\mathrm{m}^{\prime \prime} \mathrm{q}^{\prime \prime}{ }_{1}} \sin \mathrm{n} \phi^{\prime \prime}+\mathrm{C}_{\mathrm{m}^{\prime \prime} \mathrm{q}^{\prime \prime}{ }_{2}} \cos \mathrm{n} \phi^{\prime \prime}\right\} \mathrm{q}^{\prime \prime} \mathrm{d} / 2 \mathrm{~V} \sin \phi+\mathrm{C}_{\mathrm{n}}
\end{aligned}
$$

In these equations, each of the coefficients on the right-hand side is considered as a function of the angle of attack, Mach number, and fin cant. That is,

$$
\mathrm{C}_{\mathrm{Q}}=\mathrm{C}_{\mathrm{Q}}(\alpha, \mathrm{M}, \delta)
$$

The $\alpha$ or $\delta$ dependence (or both) may generally be considered as polynomial functions of these variables.

The aerodynamic coefficients appearing in the foregoing expressions are listed and described in Table I. 
TABLE I

DESCRIPTION OF VEHICLE AERODYNAMIC COEFFICIENTS

N(Input Number)

1 .

2

3

4

5

6

7

8

9

10

11

12

13

14

15

16

17

18

19

20

21

22

23

24

25

26

27
Coefficient

$\mathrm{C}_{\mathrm{X}}$

$\mathrm{C}_{\mathrm{Y}^{\prime}{ }_{0}}$

$\mathrm{C}_{\mathrm{Y}^{\prime}}$

$\mathrm{C}_{\mathrm{Y}^{\prime}}{ }_{2}$

$\mathrm{C}_{\mathrm{Y}_{\mathrm{p}}}$

$\mathrm{C}_{Z^{\prime}}{ }_{0}$

$\mathrm{C}_{\mathrm{Z}^{\prime}}$

$\mathrm{C}_{Z^{\prime}}$

$C_{1}(\delta)$

$\mathrm{C}_{1}$

$\mathrm{C}_{1_{2}}$

$\mathrm{C}_{\mathrm{p}}$

$\mathrm{C}_{\mathrm{m}^{\prime}}$

$\mathrm{C}_{\mathrm{m}^{\prime}{ }_{1}}$

$\mathrm{C}_{\mathrm{m}^{\prime}}$

$\mathrm{C}_{\mathrm{n}^{\prime}}$

$\mathrm{C}_{\mathrm{n}_{1}}$

$\mathrm{C}_{\mathrm{n}^{\prime} 2}$

$\mathrm{C}_{\mathrm{n}^{\prime}}$

$\mathrm{C}_{\mathrm{m}}$

$\mathrm{C}_{\mathrm{n}}$

$\mathrm{C}_{\mathrm{Y}_{\epsilon}}$

$\mathrm{C}_{\mathrm{Z}_{\epsilon}}$

$\mathrm{C}^{\mathrm{m}^{\prime \prime} \mathrm{q}^{\prime \prime}}$

$\mathrm{C}_{\mathrm{m}^{\prime \prime} \mathrm{q}^{\prime \prime}{ }_{1}}$

$\mathrm{C}_{\mathrm{m}^{\prime \prime} \mathrm{q}^{\prime \prime}}$

$\mathrm{C}_{1}$
Description

Axial drag

Side force

Induced side forces due to roll

orientation

N agnus force

Normal force

Induced normal forces due to roll orientation

Roll moment due to fin cant

Induced roll moments due to roll

orientation

Roll damping moment

Static pitching moment

Induced static pitching moments due to roll orientation

Static yawing moment

Induced static yawing moments due to roll orientation

Magnus moment

Pitch trim moment

Yaw trim moment

Side trim force

Normal trim force

Pitch damping moment to cross-spin orientation

Pure roll moment 


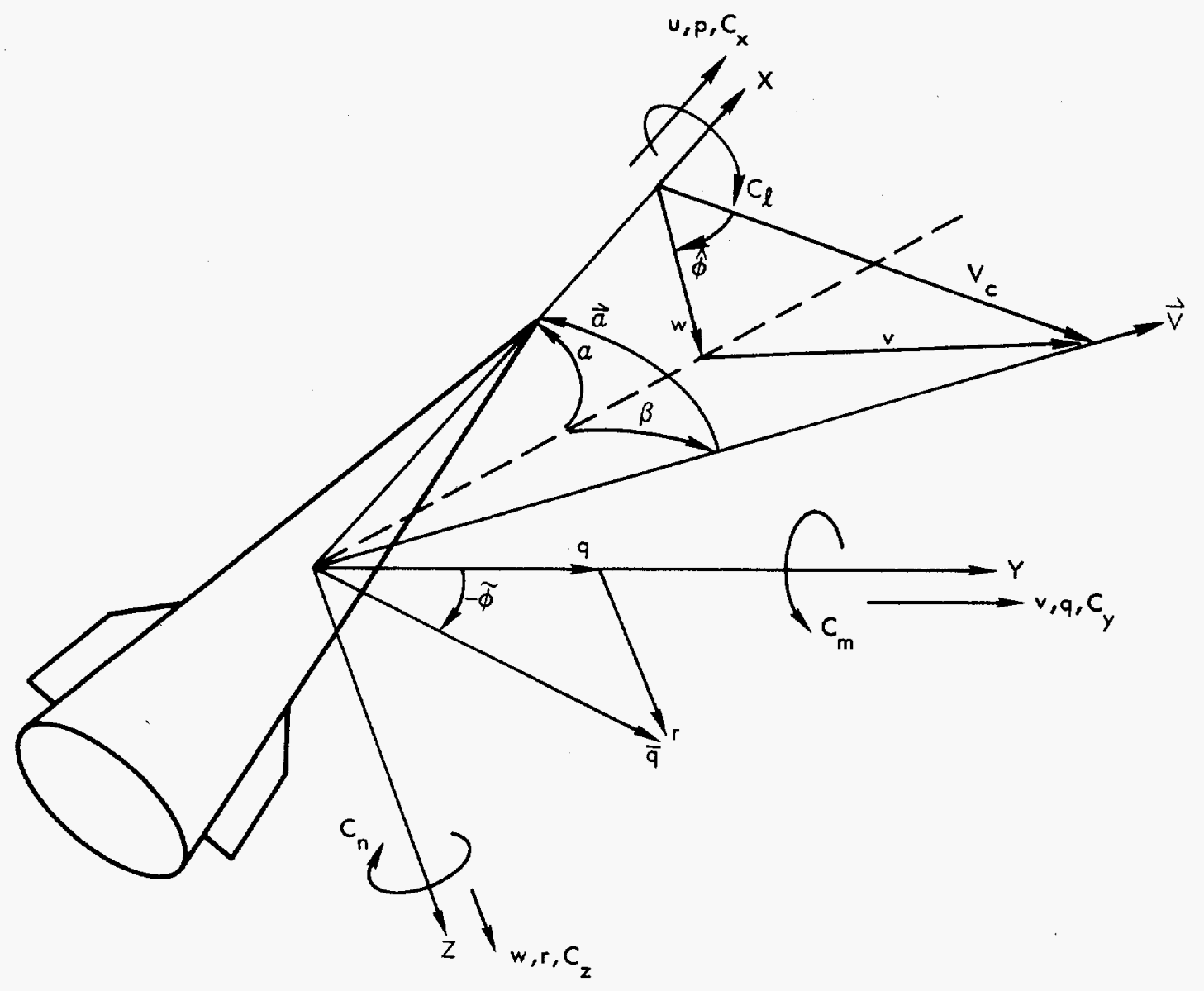

Figure 9. Aerodynamic Variables

In Figure 9, the following aerodynamic definitions are employed:

$$
\begin{aligned}
\overrightarrow{\mathrm{V}}_{\mathrm{c}} & \equiv \sqrt{\mathrm{v}^{2}+\mathrm{w}^{2}} \\
\vec{\alpha} & =\tan ^{-1} \frac{\sqrt{\mathrm{v}^{2}+\mathrm{w}^{2}}}{\mathrm{u}} \\
\hat{\phi} & =\tan ^{-1}\left(\frac{\mathrm{v}}{\mathrm{w}}\right) \\
\alpha & =\tan ^{-1}\left(\frac{\mathrm{w}}{\mathrm{u}}\right) \\
\beta & =\tan ^{-1}\left(\frac{\mathrm{v}}{\mathrm{u}}\right)
\end{aligned}
$$

Magnitude of cross velocity

Total angle of attack

Aerodynamic roll angle (angle about $\mathrm{X}$-axis from cross-velocity vector to $Z$-axis)

Angle of attack in body axes

Angle of sideslip in body axes 


$$
\begin{aligned}
& \vec{q} \equiv v \sqrt{q^{2}+r^{2}} \\
& \tilde{\phi}=\tan ^{-1}\left(\frac{-r}{q}\right)
\end{aligned}
$$

Magnitude of cross-spin

Cross-spin orientation angle (angle about $\mathrm{X}$-axis from cross-spin vector to $\mathrm{Y}$-axis)

where $u, v$, and $w$ are the projections of $\vec{v}$, the total velocity vector, on the body X, Y, $\mathrm{Z}$ axes. Therefore, the angles $\alpha^{\prime}$ and $\phi^{\prime}$ of the coefficient expansions are equivalent to the angles $\vec{\alpha}$ and $\hat{\phi}$. The variables $\mathrm{p}, \mathrm{q}$, and $r$ are the projections of $\vec{\Omega}$, the total angular velocity vector, on the body $\mathrm{X}, \mathrm{Y}, \mathrm{Z}$ axes. Consequently, $\overrightarrow{\mathrm{q}}$ and $\tilde{\phi}$ are equivalent to $\mathrm{q}^{\prime \prime}$ and $\phi^{\prime \prime}$ appearing in the coefficient expansions.

Fin Aerodynamics -- The system of variables utilized in specifying the individual fin force coefficients is shown in Figure 10. As in the previous section, $O^{\prime}, X, Y^{\prime}, Z^{\prime}$ is the cross-velocity frame with $Z^{\prime}$ in the direction of cross-velocity $(o, v, w)$. The $X, Z^{\prime}$ plane is the plane of angle of attack $\alpha^{\prime}$ with the roll orientation of a fin given by the roll angle $\phi^{\prime}$ as indicated. From arguments of symmetry, the fin normal force must be a periodic function of $m \phi^{\prime}$ since the expansion will be for a single fin. It is found that the fin normal force can be expressed as follows

$$
\begin{aligned}
\mathrm{C}_{\mathrm{N}_{\mathrm{F}}}\left(\alpha^{\prime}, \phi^{\prime}, \mathrm{M}, \delta\right)= & \mathrm{C}_{\mathrm{F}_{1}}\left(\alpha^{\prime}, \mathrm{M}, \delta\right)+\mathrm{C}_{\mathrm{F}_{2}}\left(\alpha^{\prime}, \mathrm{M}, \delta\right) \sin \phi^{\prime} \\
& +\mathrm{C}_{\mathrm{F}_{3}}\left(\alpha^{\prime}, \mathrm{M}, \delta\right) \cos \phi^{\prime}+\mathrm{C}_{\mathrm{F}_{4}}\left(\alpha^{\prime}, \mathrm{M}, \delta\right) \sin 2 \phi^{\prime} \\
& +\mathrm{C}_{\mathrm{F}_{5}}\left(\alpha^{\prime}, \mathrm{M}, \delta\right) \cos 2 \phi^{\prime}
\end{aligned}
$$

with a similar expression for the axial force. Both analytical and experimental verification of Equation (46) for finned cones have been made.

In Figure 10, the fin normal and axial force coefficients $\left(\mathrm{C}_{\mathrm{N}_{\mathrm{F}}}\right.$ and $\left.\mathrm{C}_{\mathrm{A}_{\mathrm{F}}}\right)$ are those components of the total fin force which are normal and parallel to the fin centerline respectively. Experimental data are generally available in this form. The quantities $C_{L_{F}}$ and $C_{D_{F}}$ are the fin force components which are normal and parallel to the vehicle aerodynamic centerline ( $\mathrm{X}$-axis) 


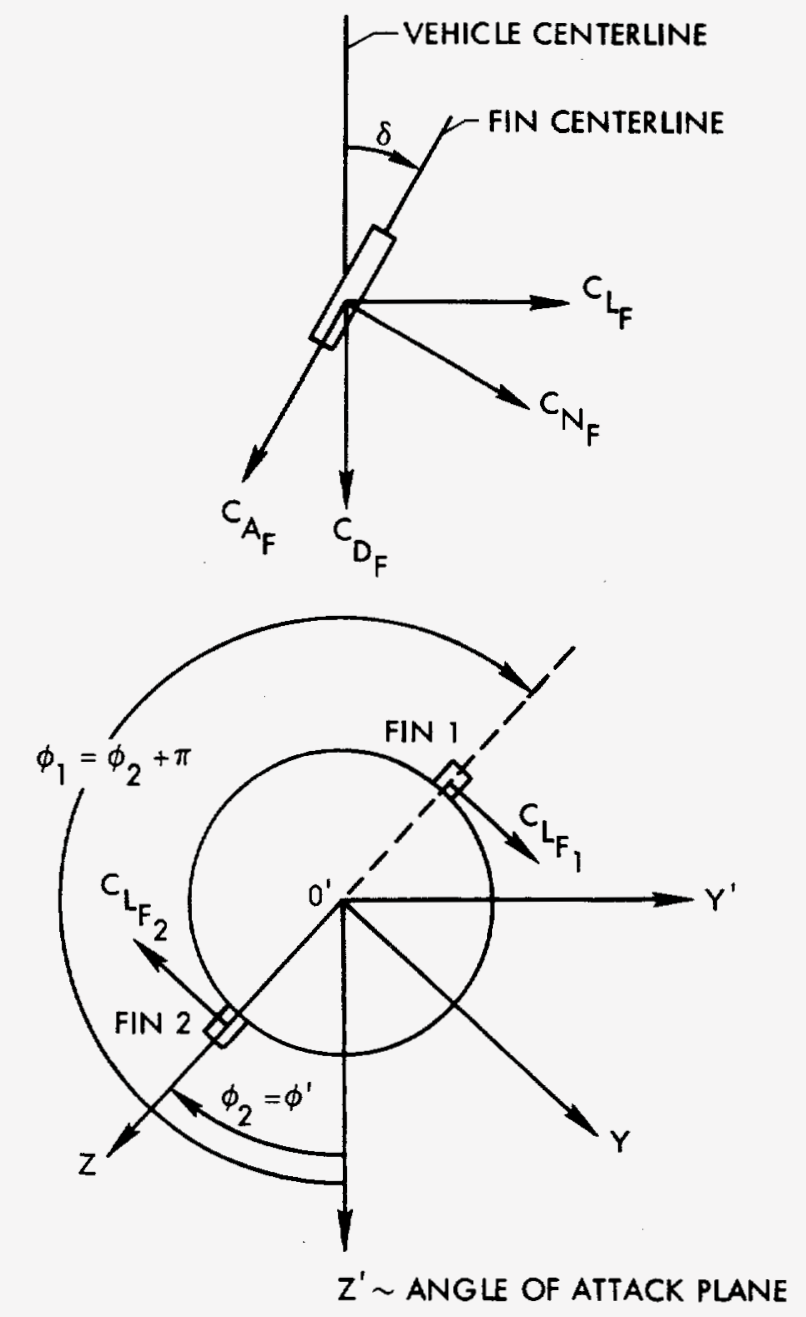

Figure 10. Fin Aerodynamic Force System

respectively. The latter coefficients are employed in the total force and moment system and are determined by

$$
\left(\begin{array}{c}
\mathrm{C}_{\mathrm{L}_{\mathrm{F}}} \\
\mathrm{C}_{\mathrm{D}_{\mathrm{F}}}
\end{array}\right)=\left(\begin{array}{cc}
\cos \delta & -\sin \delta \\
\sin \delta & \cos \delta
\end{array}\right)\left(\begin{array}{l}
\mathrm{C}_{\mathrm{F}} \\
{ }^{\mathrm{C}_{\mathrm{F}}}
\end{array}\right)
$$

For the two-finned system, the quantities $\mathrm{C}_{\mathrm{L}_{\mathrm{F}}}$ and $\mathrm{C}_{\mathrm{D}_{\mathrm{F}}}$ can be determined from the foregoing relations along with the respective roll orientations for each fin. 
The total coefficients in the body axes are then written

$$
\begin{aligned}
& C_{X}=C_{X}-C_{D_{F}}-C_{D_{2}} \\
& \mathrm{C}_{\mathrm{Y}}=\left\{\mathrm{C}_{\mathrm{Y}_{\mathrm{O}}^{\prime}}+\mathrm{C}_{\mathrm{Y}_{\mathrm{p}}^{\prime}} \mathrm{pd} / 2 \mathrm{~V}\right\} \cos \phi^{\prime}+\mathrm{C}_{\mathrm{Z}_{\mathrm{o}}^{\prime}} \sin \phi^{\prime}+\mathrm{C}_{\mathrm{L}_{\mathrm{F}_{1}}}-\mathrm{C}_{\mathrm{L}_{\mathrm{F}_{2}}}+\mathrm{C}_{\mathrm{Y}_{\epsilon}} \\
& C_{Z}=\left\{C_{Y^{\prime}}+C_{Y_{p}^{\prime}} p d / 2 V\right\} \sin \phi^{\prime}+C_{Z^{\prime}} \cos \phi^{\prime}+C_{Z_{\epsilon}} \\
& C_{1}=C_{1_{0}}+C_{1} p d / 2 V+\left\{-C_{L_{F}} z_{1_{F}}+C_{L_{F}} z_{2}{ }_{F}\right\} / d \\
& \mathrm{C}_{\mathrm{m}}=\mathrm{C}_{\mathrm{m}^{\prime}} \cos \phi^{\prime}+\left\{\mathrm{C}_{\mathrm{n}^{\prime}{ }_{\mathrm{o}}}+\mathrm{C}_{\mathrm{n}_{\mathrm{p}}^{\prime}} \mathrm{pd} / 2 \mathrm{~V}\right\} \sin \phi^{\prime}
\end{aligned}
$$

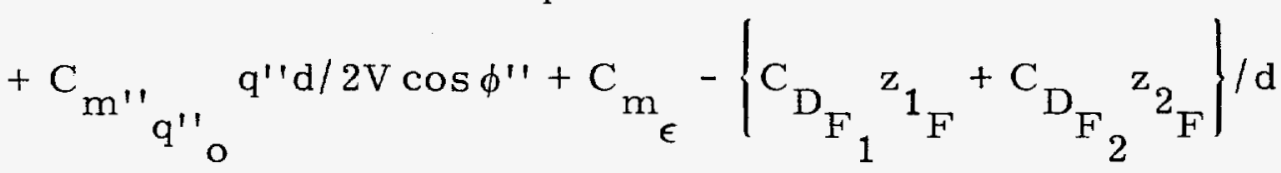

$$
\begin{aligned}
& \mathrm{C}_{\mathrm{n}}=-\mathrm{C}_{\mathrm{m}_{\mathrm{o}}^{\prime}} \sin \phi^{\prime}+\left\{\mathrm{C}_{\mathrm{n}_{\mathrm{o}}^{\prime}}+\mathrm{C}_{\mathrm{n}_{\mathrm{p}}^{\prime}} \mathrm{pd} / 2 \mathrm{~V}\right\} \cos \phi^{\prime} \\
& -\mathrm{C}_{\mathrm{m}^{\prime \prime} \mathrm{q}^{\prime \prime} \mathrm{q}^{\prime \prime d} / 2 \mathrm{~V} \sin \phi^{\prime \prime}+\mathrm{C}_{\mathrm{n}}}+\left\{\mathrm{C}_{\mathrm{L}_{\mathrm{F}}} \mathrm{x}_{1}{ }_{\mathrm{F}}-\mathrm{C}_{\mathrm{L}_{\mathrm{F}}} \mathrm{x}_{2}{ }_{\mathrm{F}} \mid / \mathrm{d}\right. \\
& +\left\{\mathrm{C}_{\mathrm{D}_{1}} \mathrm{y}_{1_{\mathrm{F}}}+\mathrm{C}_{\mathrm{D}_{\mathrm{F}}} \mathrm{y}_{2}\right\} / \mathrm{d}
\end{aligned}
$$

in which each coefficient on the right-hand side of the equations is considered a function of angle-of-attack, Mach number, and fin cant. Additionally, the variables $x_{1_{F}}, x_{2}, y_{1_{F}}, y_{2_{F}}, z_{1_{F}}, z_{2}$ are the components along $X, Y, Z$ of the fin centers-of-pressure relative to the reference point. That is,

$$
\begin{aligned}
& \vec{R}_{1_{F}}=x_{1} \vec{i}+y_{1} \vec{j}+z_{1} \vec{k} \\
& \vec{R}_{2_{F}}=x_{2} \vec{i}+y_{2} \vec{j}+z_{2} \vec{k}
\end{aligned}
$$

and in general each component is a function of angle of attack, Mach number, and fin cant. For input purposes, the fin-force coefficients and their input 
designations are listed in Table II. Quantities such as the induced side forces and yawing moments which appeared previously (see Table I) do not appear in this case; however, the effect is determined by the fin-force coefficients.

TABLE II

DESCRIPTION OF AERODYNAMIC COEFFICIENTS USED

WITH FIN AERODYNAMIC COEFFICIENT INPUT

\begin{tabular}{|c|c|c|}
\hline N(Input Number) & Coefficient & Description \\
\hline 1 & $c_{x}$ & Axial drag \\
\hline 2 & $\mathrm{C}_{\mathrm{Y}^{\prime}{ }_{0}}$ & Side force \\
\hline 3 & Not used & \\
\hline 4 & Not used & \\
\hline 5 & $\mathrm{C}_{\mathrm{Y}_{\mathrm{p}}}$ & Magnus force \\
\hline 6 & $\mathrm{C}_{Z_{0}}$ & Normal force \\
\hline 7 & $\mathrm{C}_{\mathrm{F}_{1}}$ & \\
\hline 8 & $\mathrm{C}_{\mathrm{F}_{2}}$ & \\
\hline 9 & $\mathrm{C}_{\mathrm{F}_{3}}$ & $\begin{array}{l}\text { Coefficients of the expansion for } \\
\mathrm{C}_{\mathrm{N}_{\mathrm{T}}} \text { given by Equation }(46)\end{array}$ \\
\hline 10 & $\mathrm{C}_{F_{4}}$ & \\
\hline 11 & $\mathrm{C}_{F_{5}} J$ & \\
\hline 12 & $\mathrm{C}_{1_{\mathrm{p}}}$ & Roll damping moment \\
\hline 13 & $\mathrm{C}_{\mathrm{m}^{\prime} \mathrm{O}}$ & Static pltching moment \\
\hline 14 & $\mathrm{C}_{\mathrm{A}_{F}}$ & Fín axial force coefficient \\
\hline 15 & Not used & \\
\hline 16 & $\mathrm{C}_{\mathrm{n}^{\prime}{ }_{0}}$ & Static yawing moment \\
\hline 17 & Not used & \\
\hline 18 & Not used & \\
\hline 19 & $\mathrm{C}_{\mathrm{n}^{\prime}}$ & Magnus moment \\
\hline 20 & $\mathbf{c}_{\mathrm{m}_{\epsilon}}$ & Pitch trim moment \\
\hline 21 & $\mathrm{C}_{n_{6}}$ & Yaw trim moment \\
\hline 22 & $\mathbf{C}_{\mathbf{Y}}$ & Side trim force \\
\hline 23 & $\mathrm{c}_{\mathrm{z}}$ & Normal trim force \\
\hline 24 & $\mathrm{c}_{\mathrm{m}^{\prime \prime}} \mathrm{q}_{0}$ & Pitch damping moment \\
\hline 25 & Not used & \\
\hline 26 & Not used & \\
\hline 27 & $\mathrm{c}_{1_{0}}$ & Pure roll moment \\
\hline 28 & c & $\begin{array}{l}\text { Fin center-of-pressure offet } \\
\text { Equations (37) and (38) }\end{array}$ \\
\hline
\end{tabular}

Fin center-of-pressure offet 


\section{Description of and User's Guide for the SPINFIN Trajectory Simulation Computer Program}

Description of Problem Solution

The SPINFIN program computes a trajectory and associated missile performance variables from initial launch conditions to some desired cutoff altitude or time. A provision is made so that atmospheric properties for an observed atmosphere may be supplied by a user-written subroutine. Alternatively, an ARDC 1962 standard-model atmosphere is included as part of the formulation.

The solution of a desired trajectory is performed in three phases: input, numerical integration, and edit. Assignment of initial values of variables, input of control and missile parameters, and input of vehicle aerodynamics are performed in the input phase of the problem. Care has been taken to make the SPINFIN input as closely compatible as possible with the other SLL trajectory computer program. Secondly, the equations of motion are numerically integrated using an Adams-Moulton predictorcorrector scheme with automatic step-size reduction. During this phase, data points are stored on either disc or magnetic tape at user-specified intervals. Lastly, an editing phase provides output in specified sets of variables to facilitate detailed investigations. It is possible to obtain as output a standard set of variables and/or up to six additional sets of variables. Storage of variables in phase two facilitates plotting with a printer plotting routine, CRT plots, or by means of user-written or "canned" plotting routines which are available in the SLL program library.

General Description of Input

SPINFIN has been programmed for ease in entering input data and is directed toward providing a multi-run capability. Data for several trajectories can be stacked in the input data deck and each trajectory can be computed in one job. The program continues to read cards until a RUN card is encountered; at that time, the desired trajectory is computed. At the completion of each trajectory computation, the required output is listed, and the program continues to read cards until either the end of the data deck or another RUN card is encountered. A typical data deck thus consists of a set of cards which contains all information required for the first trajectory followed by a RUN card. Then, to run each subsequent case, only those parameters which are to be changed need be input and followed by a RUN card. These capabilities are accomplished through the use of alphanumeric symbols placed in the first field of data to identify these cards to the program. 

follows:

The general categories of input to the SPINFIN program are as

1. Program Control Parameters: An identifying title, editing, printing, and plotting indicators are specified as desired.

2. Trajectory Initialization Parameters: Included are initial trajectory altitude as well as vehicle initial velocity, altitude, etc.

3. Vehicle Mass and Inertia Properties: Capability exists for full inertia tensor as well as general center-of-mass offset.

4. Roll Control System Parameters: A complete specification of all control system physical properties, friction constants, etc. is performed.

5. Aerodynamic Coefficient Input: The comprehensive set of aerodynamics previously described may be input as:

a. Polynomial functions

b. Single tabular arrays

c. Two-dimensional tables

6. Aerodynamic Coefficient Scaling and Altitude Dependent Effects: The coefficient scaling factors include a constant scale factor so that an aerodynamic coefficient may be altered (scaled) without its being necessary to enter another set of data. Altitude scale factors may be entered which allow any of the aerodynamic coefficients to vary with altitude. These provide a capability for simulating such phenomena as fin ablation, trim-angle variation, etc. Included under this input is a provision for altitudedependent fin-trim angles as well as a capability for modeling slowly varying vehicle center-of-mass offset.

7. A RUN Card: This card signifies the start of the trajectory computation.

Detailed Description of Input

The following is a description of the SPINFIN input cards given according to the categories previously listed. Included with the description of each input data card is the standard FORTRAN format statements under which the card is read. Unless otherwise stated, the order of the input cards does not matter. The program will use the last value of each variable entered for the trajectory computation. Default values when a field is left blank are indicated when appropriate. A RUN card signifies the end of a set of input and the start of the computation phase. 


\section{Program Control Parameter}

A. Title Card

Format (A10, 10A7)

Card Cols. $\quad$ Contents

1-5 TITLE

11-80 Identifying title for run (any acceptable machine characters)

B. Control card

Format (A10, 6I5, 6I1, 4X6I1)

Card Cols. $\quad$ Contents

$1-7$

CONTROL

$11-15$

NPRNT

Specifies number of starting integration time steps between output print lines and/or data points stored on disc or magnetic tape (default: 1 - print at each step)

NCNTRL

Roll-control system option number

0 - no roll control

1 - coupled fins

2 - uncoupled fins (default: zero)

NBDY

Aerodynamic coefficient option

0 - total body aerodynamics

1 - fin aerodynamics

26-30 IPRNT

Standard output print indicator

0 - do not print standard output set

1 - print standard output set (Table VI) (default: zero)

IPLOT

Standard printer plot indicator

0 - do not plot

1 - normal page plots of standard plot set (Table VIII)

2 - continuous page plots of standard plot set (Table VIII) 
Card Cols.

$36-40$

ICRT

$41-46$

$51-56$

$61-66$
CRT standard plot indicator

0 - do not plot

1 - CRT plots of standard plot set (Table VIII) versus time

2 - CRT plots of standard plot set versus altitude

These columns are used to select which of the six supplementary tables of output are to be printed. A non-zero integer in any of these columns results in the corresponding output set being printed (see Table VII) (default: zero)

These columns are used to select which of the six supplementary tables of output are to be plotted on printer plots. A non-zero integer in any of these columns results in the corresponding output set being plotted (see Table VII)

0 (a blank) - do not plot

1 - plot variables versus time

2 - plot variables versus altitude

These columns are used to select which of the six supplementary tables of output are to be plotted on CRT plots. A non-zero integer in any of these columns results in the corresponding output set being plotted (see Table VII)

0 (a blank) - do not plot

1 - plot variables versus time

2 - plot variables versus altitude 
2. Trajectory Initialization Parameters

Format (A10, 7F10.0)

A. Start card (Initialization parameters)

Card Cols. $\quad$ Contents

1-5 START

\begin{tabular}{|c|c|c|}
\hline $11-20$ & $\mathrm{~T} 1$ & Starting time - s \\
\hline $21-30$ & $\mathrm{DT}$ & $\begin{array}{l}\text { Starting integration step size }-s \\
\text { (default: } 0.005)\end{array}$ \\
\hline $31-40$ & $\mathrm{ALT}$ & Initial altitude - $\mathrm{ft}$ \\
\hline $41-50$ & $\mathrm{~V}$ & Initial velocity - ft/s \\
\hline $51-60$ & THV & $\begin{array}{l}\text { Flight path angle - deg } \\
\text { (positive upward) }\end{array}$ \\
\hline $61-70$ & $\mathrm{TC}$ & $\begin{array}{l}\text { Trajectory termination time }-s \\
\text { (default: no time cutoff) }\end{array}$ \\
\hline $71-80$ & $\mathrm{YC}$ & $\begin{array}{l}\text { Trajectory termination altitude } \\
\text { (default: terminated at zero } \\
\text { altitude) }\end{array}$ \\
\hline
\end{tabular}

B. Angle card (Initial attitude angles and angular velocities) Card Cols. $\quad$ Contents

$\left.\begin{array}{clll}1-5 & \text { ANGLE } & \\ 11-20 & \alpha & \text { Initial angle of attack } \\ 21-30 & \beta & \text { Initial angle of sideslip }\end{array}\right\}$ deg


3. Vehicle Mass and Inertia Properties

Format (A10,7F10.0)

A. Mass card (Vehicle mass properties)

$$
\begin{aligned}
& \text { Card Cols. } \quad \text { Contents } \\
& \text { 1-4 MASS } \\
& \text { 11-20 d Vehicle base diameter (reference } \\
& \text { length for aerodynamic coefficients) } \\
& \text { - ft } \\
& \text { 21-30 } \mathrm{m} \quad \text { Vehicle mass - slugs } \\
& 31-40 \quad \mathrm{x}_{0} \\
& 41-50 \quad \mathrm{y}_{0} \\
& 51-60 \quad z_{0}
\end{aligned}
$$

\begin{tabular}{|c|c|c|c|}
\hline $1-7$ & INERTIA & & \\
\hline $11-20$ & $\mathrm{I}_{\mathrm{X}}$ & Roll moment of inertia & \\
\hline $21-30$ & $\mathrm{I}_{\mathrm{Y}}$ & Pitch moment of inertia & $\operatorname{slug} / \mathrm{ft}^{2}$ \\
\hline $31-40$ & $I_{Z}$ & Yaw moment of inertia & \\
\hline $41-50$ & IXY & \multirow{3}{*}{\multicolumn{2}{|c|}{ Products of inertia - slug/ft ${ }^{2}$}} \\
\hline $51-60$ & IXZ & & \\
\hline $61-70$ & IYZ & & \\
\hline
\end{tabular}

B. Inertia card (Vehicle inertia properties)

Card Cols. Contents


4. Roll-Control System Parameters

Format (A10, 7F10.0)

A. Spring-mass parameters

Card Cols. Contents

1-5 ROLL1

$\left.\begin{array}{ll}11-20 & \text { M1 - Control mass - slugs } \\ 21-30 & \text { K1 - Spring constant }-\mathrm{lb} / \mathrm{ft} \\ 31-40 & \mathrm{C} 1-\text { Damping coefficient }-\mathrm{lb}-\mathrm{s} / \mathrm{ft}\end{array}\right\}$ Assembly 1

B. Control mass positions in body system

Card Cols. $\quad$ Contents

1-5 ROLL2

\begin{tabular}{|c|c|c|}
\hline $1-20$ & $\mathrm{X} 1$ & \multirow{6}{*}{$\begin{array}{l}\text { Control mass center-of-mass } \\
\text { displacements from reference } \\
\text { point along body } \mathrm{X}_{\mathrm{c}} \cdot \mathrm{Z}_{\mathrm{c}} \cdot \mathrm{Y}_{\mathrm{c}} \text { axes } \\
\text { respectively - ft } \\
\text { (Values of } \mathrm{R} 10 \text { and } \mathrm{R} 20 \text { correspond } \\
\text { to mass position for non-loaded } \\
\text { spring) }\end{array}$} \\
\hline $21-30$ & $\mathrm{X} 2$ & \\
\hline $31-40$ & $\mathrm{Z} 1$ & \\
\hline $41-50$ & $\mathrm{Z} 2$ & \\
\hline $51-60$ & $\mathrm{R} 10$ & \\
\hline $1-70$ & R20 & \\
\hline
\end{tabular}


C. Control mass inner and outer stops along $Y_{c}$ axis

Card Cols. Contents

$\left.\begin{array}{cl}1-5 & \text { ROLL3 } \\ 11-20 & \text { R1I } \\ 21-30 & \text { R2I } \\ 31-40 & \text { R1M } \\ 41-50 & \text { R2M } \\ 51-60 & \text { R1S } \\ 61-70 & \text { R2S }\end{array}\right\}$

Inner stops for control masses

1 and 2 respectively - $\mathrm{ft}$

Outer stops for control masses

1 and 2 respectively $-\mathrm{ft}$

Initial mass positions - $\mathrm{ft}$

All quantities are along $\mathrm{Y}_{\mathrm{c}}$

(If not specified, initial position is determined from steady-state solution of Equations (33) and (34) or Equation (43) when appropriate)

D. Fin locations in body system

Card Cols. $\quad$ Contents

$\begin{array}{cl}1-5 & \text { ROLL4 } \\ 11-20 & \text { X1F } \\ 21-30 & \text { X2F } \\ 31-40 & \text { Y1F } \\ 41-50 & \text { Y2F } \\ 51-60 & \text { Z1F } \\ 61-70 & \mathrm{Z} 2 \mathrm{~F}\end{array}$

Fin center-of-pressure displacements from reference point along body $\mathrm{X}, \mathrm{Y}, \mathrm{Z}$ axes respectively - $\mathrm{ft}$

E. Maximum and minimum fin cants

Card Cols. $\quad$ Contents

$$
1-5
$$

ROLL5

$11-20$

DMAX1

$21-30$

DMIN1

Maximum fin cant - deg

$31-40$

DMAX2

41-50

DMIN2

Minimum fin cant - deg

Fin 1

Maximum fin cant - deg

Minimum fin cant - deg

Fin 2 
F. Friction force parameters

Card Cols. Contents

1-5 ROLL6

$\begin{array}{ccc}11-20 & f & \begin{array}{l}\text { - } \\ \text { friction force - lb }\end{array} \\ 21-30 & \bar{\mu} & -\begin{array}{l}\text { Friction force proportionality } \\ \text { constant relating total fin aero- } \\ \text { dynamic force to a mechanism } \\ \text { friction force }\end{array} \\ & & - \\ 31-40 & \hat{\mu} & \text { Friction force proportionality } \\ & \text { constant relating total vehicle } \\ & \text { axial acceleration (in } \mathrm{g} \text { 's) to a } \\ & \text { mechanism friction force. } \\ & \text { (These values are described } \\ & \text { by Equation (35)) }\end{array}$

G. Control mass axis orientation

Card Cols. $\quad$ Contents

1-5 ROLL7

$\left.\begin{array}{ll|l}11-20 & \phi_{1 \mathrm{c}} \\ 21-30 & \psi_{1 \mathrm{c}} & \begin{array}{l}\text { Orientation angles of control mass 1 } \\ \text { axis of motion relative to body axes } \\ \text { (deg) } \\ 41-40\end{array} \phi_{2 \mathrm{c}} \\ \psi_{2 \mathrm{c}}\end{array}\right\} \begin{aligned} & \text { Orientation angles of control mass 2 } \\ & \text { axis of motion (deg) relative to } \\ & \text { body axis (see Figure 5) }\end{aligned}$

H. Fin cant bias (Fin trim angles)

Card Cols. Contents

$\left.\begin{array}{cc}1-5 & \text { ROLL8 } \\ \text { 11-20 } & { }^{\delta} \mathrm{T}_{1} \\ & \delta \mathrm{T}_{2}\end{array}\right\} \quad \begin{aligned} & \text { Fin-cant trim angles for fins } 1 \text { and } \\ & 2 \text { respectively - deg }\end{aligned}$


5. Aerodynamic Coefficient Input

As suggested in Equation (27) and Table I, up to 28 aerodynamic coefficients may be input to SPINFIN. Each coefficient can be entered by one of the following methods:

- Polynomial functions of angle-of-attack to fifth order: A different polynomial may be input for each of 12 different Mach numbers and 5 different fin cants for each Mach number.

- Single tabular functions of angle-of-attack or Mach numbers: These arrays are limited to 10 angles-of-attack or $12 \mathrm{Mach}$ numbers.

- Tabular functions of both Mach number and angle-of-attack: Double tables may have up to $12 \mathrm{Mach}$ numbers and, associated with each $\mathrm{Mach}$ number, up to 10 distinct values of angle-of-attack.

Although there is a capability for extensive aerodynamics, the input is straightforward. Each aerodynamic coefficient input must be initiated by an identifying card which indicates the coefficient to be entered and the method of input. The first card appears as follows:

\section{AEROCOEF card}

Format (A10, A10, 2I5)

\section{Card Cols. $\quad$ Contents}

$$
\begin{array}{cl}
1-8 & \text { AEROCOEF } \\
11-20 & \text { Name - Alphanumeric identification of coefficient } \\
21-25 & \mathrm{~N}-\text { Coefficient numerical designation (input number } \\
\text { shown in Tables I and II) } & \\
26-30 & \mathrm{~K}-\text { Type of input } \\
& \text { 1 - Polynomials } \\
& \text { 2 - Single table } \\
& \text { 3 - Double table }
\end{array}
$$

The remaining cards for each aerodynamic coefficient depend on the input option (polynomials, single table, or double table). Each type of input is discussed in the following pages. 
A. Polynomial coefficient input

The polynomial coefficient type of input is the most comprehensive aerodynamic coefficient input. Under this option, the aerodynamic coefficients can be functions of $\mathrm{Mach}$ number, angle-of-attack, fin cant, and roll orientation angle; or any combination of these variables. Note also that a constant coefficient may be input under this option. To permit this generality and allow input of large quantities of data, each aerodynamic coefficient is input as polynomial functions of the angle-of-attack for each of several Mach numbers and each of several fin cants. This amounts to entering the coefficients as two-dimensional tables of polynomials according to

$$
\left.\begin{array}{rl}
\left.\mathrm{C}_{\mathrm{i}}(\alpha)\right|_{\mathbb{M}}=\mathrm{M}_{1} \\
\delta=\delta_{\mathrm{k}}
\end{array} \sum_{\mathrm{j}=0}^{5} \overline{\mathrm{C}}_{\mathrm{j}} \alpha^{\mathrm{j}} \quad \text { ( } \alpha \text { in radians }\right)
$$

for each $M$ ach number, $M_{1}$, and each fin cant, $\delta_{k}$. A different polynomial may be input for each of 12 different Mach numbers and five different fin cants for each Mach number. There are three basic types of cards for polynomial input:

(1) Polynomial input card, type 1

Format (1615)

\begin{tabular}{|c|c|}
\hline Card Cols. & Contents \\
\hline $1-5$ & NMACH \\
\hline $6-10$ & NDL1 \\
\hline $11-15$ & NDL2 \\
\hline $16-20$ & NDL3 \\
\hline etc. & etc. \\
\hline
\end{tabular}

Integer specifying number of Mach numbers for which polynomials will be entered.

Integers specifying number of fin cants for each $\mathrm{Mach}$ number for which polynomials will be entered. The numbers of fin cants may be different for each Mach number.

(As required) 
Corresponding to each Mach number, a set of cards is entered which gives the geometric fin cants and coefficient polynomials. This information is input as follows:

Polynomial input card, type 2

Format $(8 \mathrm{~F} 10.0)$

Card Cols. $\quad$ Contents

$\left.\begin{array}{rl}1-10 & \text { MACH } \\ 11-20 & \text { DEL1 } \\ 21-30 & \text { DEL2 } \\ 31-40 & \text { DEL3 } \\ 41-50 & \text { DEL4 } \\ 51-60 & \text { DEL5 }\end{array}\right\} \quad \begin{aligned} & \text { Mach number } \\ & \text { Values of fin cant for which poly- } \\ & \text { nomials will be entered for the } \\ & \text { given Mach number. Fin cants } \\ & \text { must be entered in monotonically } \\ & \text { increasing order. }\end{aligned}$

Corresponding to each fin cant, the following polynomial card is input:

(3) Polynomial input card, type 3

Format $(8 \mathrm{~F} 10.0)$

Card Cols. $\quad \underline{\text { Contents }}$

$\left.\begin{array}{cc}1-10 & \overline{\mathrm{C}}_{0} \\ 11-20 & \overline{\mathrm{C}}_{1} \\ 21-30 & \overline{\mathrm{C}}_{2} \\ 31-40 & \overline{\mathrm{C}}_{4} \\ 41-50 & \overline{\mathrm{C}}_{5}\end{array}\right\} \quad \begin{aligned} & \text { Coefficients of the polynomial } \\ & \text { expansion given by the expression }\end{aligned}$

The details of this type of coefficient input are perhaps best illustrated by an example. Let it be desired to enter the fin normal force coefficient, $\mathrm{C}_{\mathrm{F}_{1}}$ (input number $=7$ given in $\mathrm{T}$ able $\mathrm{II}$ ), which is known as a function of Mach number and fin cant as in the polynomial functions: 


$$
\begin{aligned}
& \mathrm{Mach}=5 \\
& \delta=-5 .^{\circ} \quad \mathrm{C}_{\mathrm{F}_{1}}=5.10 \times 10^{-4}-4.20 \times 10^{-3} \alpha^{2}+1.29 \times 10^{-2} \alpha^{4} \\
& \delta=0.0^{\circ} \quad \mathrm{C}_{\mathrm{F}_{1}}=0 \\
& \delta=5 .^{\circ} \quad \mathrm{C}_{\mathrm{F}_{1}}=5.10 \times 10^{-4}+4.20 \times 10^{-3} \alpha^{2}-1.29 \times 10^{-2} \alpha^{4} \\
& \mathrm{Mach}=10 \\
& \delta=-5 . \\
& \mathrm{C}_{\mathrm{F}_{1}}=-5.62 \times 10^{-4}-3.93 \times 10^{-3} \alpha^{2}+7.54 \times 10^{-3} \alpha^{4} \\
& \delta=2.5^{\circ} \\
& \mathrm{C}_{\mathrm{F}_{1}}=-2.48 \times 10^{-4}-2.67 \times 10^{-3} \alpha^{2}+7.9 \times 10^{-3} \alpha^{4} \\
& \delta=0 .^{\circ} \\
& \mathrm{C}_{\mathrm{F}_{1}}=0 \text {. } \\
& \delta=2.5^{\circ} \\
& \mathrm{C}_{\mathrm{F}_{1}}=2.48 \times 10^{-4}+2.67 \times 10^{-3} \alpha^{2}-7.9 \times 10^{-3} \alpha^{4} \\
& \delta=5 .^{\circ} \\
& \mathrm{C}_{\mathrm{F}}=5.62 \times 10^{-4}+3.93 \times 10^{-3} \alpha^{2}-7.54 \times 10^{-3} \alpha^{4}
\end{aligned}
$$

The data cards necessary for entering this information are given in Figure 11. 
B. Single table coefficient input

Under this option, the aerodynamic coefficients are entered as tabular functions of either $\mathrm{Mach}$ number or angle-of-attack. In either case, the values of the independent variable must be entered in monotonically increas ing order. The maximum number of independent variable entries is limited to 10 for an angle-of-attack table and 12 for a Mach number table. Following the AEROCOEF card, two types of data cards are required for single table array input:

(1) Single table card, type 1

Format (2I5)

Card Cols. Contents

$1-5 \quad$ NV

Integer specifying the total number of values to be entered (twice the $6-10 \quad$ IV number of independent variables).

Integer specifying independent variable

0 (or blank) - Table is a function of angle-of-attack

1 - Table is a function of Mach number

(2) Single table card, type 2 (as needed)

Format $(8 \mathrm{~F} 10.0)$

$\begin{array}{rll}\text { Card Cols. } & & \text { Contents } \\ 1-10 & & \alpha \text { or } \mathrm{M} \\ 11-20 & & \text { Coefficient } \\ 21-30 & & \alpha \text { or } \mathrm{M} \\ 31-40 & & \text { Coefficient } \\ 41-50 & & \alpha \text { or } \mathrm{M} \\ 51-60 & & \text { Coefficient } \\ 61-70 & & \alpha \text { or } M \\ 71-80 & & \text { Coefficient }\end{array}$


Given the tabular values of the aerodynamic damping derivative coefficient $\left(\mathrm{C}_{\mathrm{M}_{\mathrm{q}}}+\mathrm{C}_{\mathrm{M}_{\dot{\alpha}}}\right.$, input number 24 in $\left.\mathrm{Table} \mathrm{I}\right)$ as functions of $\mathrm{Mach}$ number shown in Table III, the necessary data cards for input to the program are described in Figure 12.

TABLE III

TABULAR REPRESENTATION OF COEFFICIENT DATA VERSUS IMACH NUMBER

$\underline{\text { Mach }}$

0

0.8

1.2

1.5

2.5

3. 0

4. 0

5. 0

10.0

20.0

$$
\mathrm{C}_{\mathrm{M}}+\mathrm{C}_{\mathrm{M}_{\dot{\alpha}}}
$$

$-1.7$

$-1.7$

$-7.1$

$-4.8$

$-2.9$

$-2.5$

$-2.2$

$-2.1$

$-2.0$

$-2.0$ 
11111111112222222222333333333344444444445555555555666656666677777777778 12345679901234567990123456789012345678901234567890123450789012345678901234567890

THE NUMBERS ABOVE SHOW THE GARD COLUMNS

\begin{tabular}{|c|c|c|c|c|c|c|c|}
\hline $\begin{array}{c}A E R O C O E F \\
20\end{array}$ & $1^{C M n}$ & 24 & 2 & & & & \\
\hline $\begin{array}{l}0 . \\
2.5 \\
10 .\end{array}$ & $\begin{array}{l}-1.7 \\
-2.94 \\
-2 .\end{array}$ & $\begin{array}{l}.8 \\
3 . \\
20\end{array}$ & $\begin{array}{l}-1.7 \\
-2.5 \\
-2.0\end{array}$ & $\begin{array}{l}1.2 \\
4 .\end{array}$ & $\begin{array}{l}-7.1 \\
-2.13\end{array}$ & $\begin{array}{l}1.5 \\
5 .\end{array}$ & $\begin{array}{l}-4.8 \\
-2.18\end{array}$ \\
\hline
\end{tabular}

Figure 12. Description of Single Table Input 
C. Double table coefficient input

Aerodynamic coefficients may be specified as two-dimensional, tabular arrays of angle-of-attack and Mach number. The double tables may have up to 12 independent values of Mach number, and associated with each $\mathrm{Mach}$ number, up to 10 distinct values of angle-of-attack. Both Mach numbers and angles-of-attack must be input in monotonically increasing order. These tables are broken up into groups of four Mach numbers with the associated angles-of-attack and coefficients. In each set, the number of angles-of-attack must be the same for each Mach number. The values of angle-of-attack need not be the same for each Mach number, nor need they be in even or equal increments. There are four types of data cards utilized in double table input:

(1) Double table card, type 1

Format (I5)

Card Cols. $\quad$ Contents

$1-5 \quad$ NMS

Number of Mach number sets. There are four Mach numbers contained in each set except the last, which may have one to four Mach numbers.

(2) Double table card, type 2

Format (I5)

Card Cols. $\quad$ Contents 1-5 NAS

Number of angle-of-attack values associated with each $\mathrm{Mach}$ number must be the same for each $\mathrm{Mach}$ number in a set. The angle-ofattack values need not be the same. This is repeated at the start of each set. 
(3)

Double table card, $:$ type 3

Format (4F20.0)

Card Cols. Contents

$\begin{array}{lll}1-20 & \text { MACH 1 } & \text { Mach number } \\ 21-40 & \text { MACH 2 } & \text { Mach number } \\ 41-60 & \text { MACH 3 } & \text { Mach number } \\ 61-80 & \text { MACH 4 } & \text { Mach number }\end{array}$

(4) Double table card, type 4

Format $(8 \mathrm{~F} 10.0)$

This card contains four 20-column fields corresponding to the Mach number fields of the type 3 card. Each field is subdivided into two 10-column fields for angle-of-attack and coefficient values, respectively.

\begin{tabular}{|c|c|}
\hline Card Cols. & Contents \\
\hline $1-10$ & $\alpha$ - Angle-of-attack (deg) \\
\hline $11-20$ & Coefficient \\
\hline $21-30$ & $\alpha$ \\
\hline $31-40$ & Coefficient \\
\hline $41-50$ & $\alpha$ \\
\hline $51-60$ & Coefficient \\
\hline $61-70$ & $\alpha$ \\
\hline $71-80$ & Coefficient \\
\hline
\end{tabular}

Consequently, there are NAS type 4 cards associated with each Mach number set. Shown in Table IV is a two-dimensional tabular representation of axial force coefficient, $C_{X}$ (input number 1 in $T$ able I) as a function of $M$ ach number and angle-of-attack. 


\section{TABLE IV}

\section{TABULAR REPRESENTATION OF AERODYNAMIC COEFFICIENT DATA VERSUS MACH NUMBER AND ANGLE-OF-ATTACK}

Mach Number

\begin{aligned} & \multicolumn{2}{c}{0} \\ & \hline$\alpha \multicolumn{1}{c}{\mathrm{C}_{\mathrm{X}}} \\ &$\hline 0.0-0.2 \\ & 1.0-0.201 \\ & 2.5-0.207 \\ & 5.5-0.21 \\ & 10.0-0.22 \\ & 16.0-0.23 \\ & 20.0-0.24 \\ & 35.0-0.30\end{aligned}

\begin{tabular}{rc}
\multicolumn{2}{c}{10.0} \\
\hline$\alpha$ & $\mathrm{C}_{\mathrm{X}}$ \\
\hline 0.0 & -0.064 \\
5.0 & -0.067 \\
10.0 & -0.072 \\
15.0 & -0.078 \\
20.0 & -0.088 \\
30.0 & -0.148 \\
60.0 & -0.392
\end{tabular}

\begin{aligned} & \multicolumn{2}{c}{1.0} \\ & \hline$\alpha \multicolumn{1}{c}{\mathrm{C}_{\mathrm{X}}} \\ &$\hline 0.0-0.54 \\ & 1.4-0.55 \\ & 2.0-0.583 \\ & 7.0-0.63 \\ & 12.0-0.69 \\ & 18.0-0.715 \\ & 20.0-0.72 \\ & 40.0-0.831\end{aligned}

20.0

\begin{aligned} & \hline \multicolumn{2}{c}{20.0} \\ & \hline 0.0 \multicolumn{1}{c}{$\mathrm{C}_{\mathrm{X}}$} \\ & \hline 5.0-0.053 \\ & 10.0-0.061 \\ & 15.0-0.070 \\ & 20.0-0.09 \\ & 30.0-0.15 \\ & 60.0-0.43\end{aligned}

\begin{aligned} & \multicolumn{2}{c}{2.2} \\ & \hline$\alpha \multicolumn{1}{c}{\mathrm{C}_{\mathrm{X}}} \\ &$\hline 0.0-0.31 \\ & 2.0-0.316 \\ & 2.5-0.318 \\ & 6.0-0.321 \\ & 12.0-0.344 \\ & 18.0-0.35 \\ & 20.0-0.365 \\ & 32.0-0.45\end{aligned}

30.0

\begin{aligned} & \multicolumn{2}{c}{30.0} \\ & \hline$\alpha \multicolumn{1}{c}{\mathrm{C}_{\mathrm{X}}} \\ &$\hline 0.0-0.053 \\ & 5.0-0.061 \\ & 10.0-0.068 \\ & 15.0-0.075 \\ & 20.0-0.093 \\ & 30.0-0.16 \\ & 60.0-0.45\end{aligned}

The input cards required to enter these data are provided in Figure 13. 
11111111112222222222373333333344444444445555555555666666660677777777773 $123456799012345678991234567990123+567990123+567990123456789012345673901234567990$

THE NUMBERS ABOVE SHOW THE CARD COLUMNS

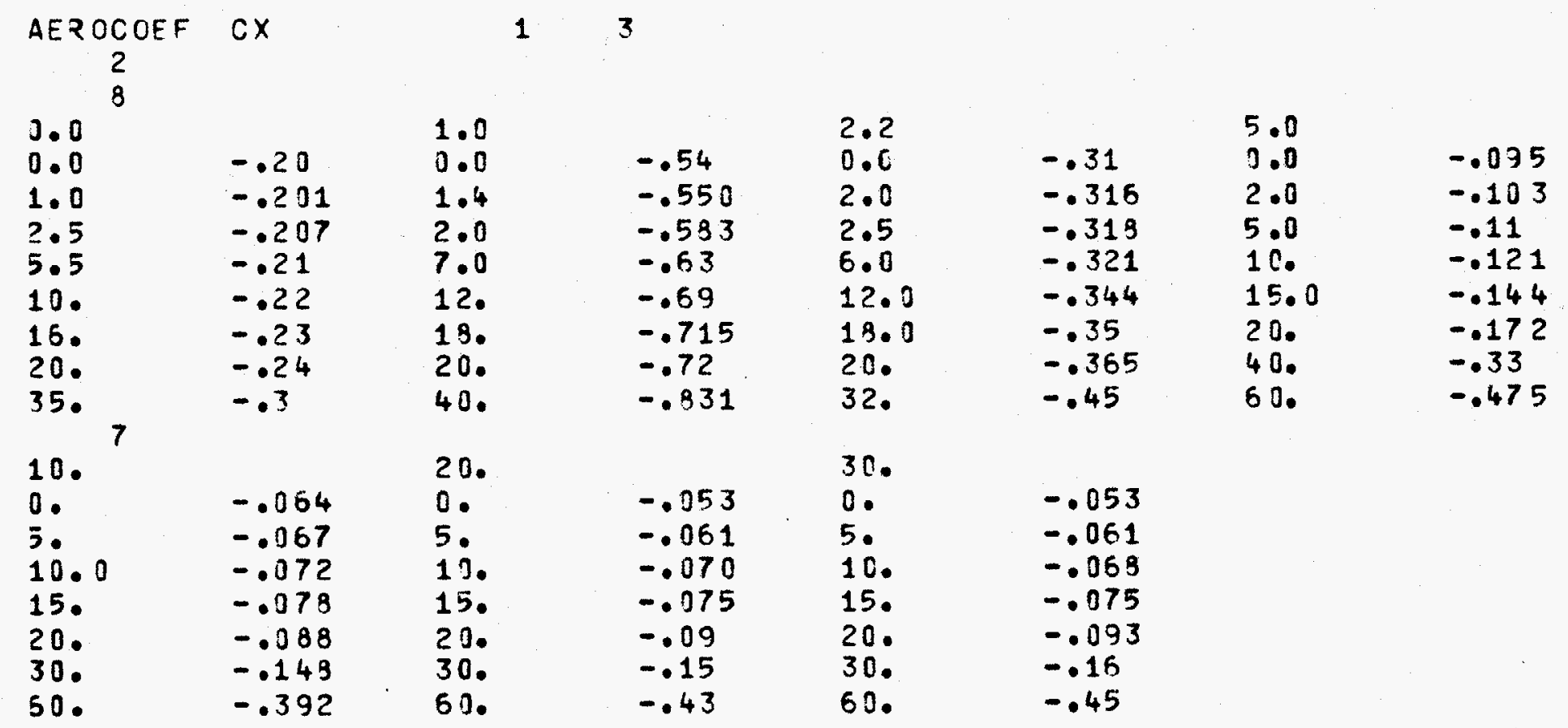

Figure 13. Description of Double Table Input 


\section{Scaling of Aerodynamic Coefficients}

Two types of aerodynamic coefficient scaling factors may be input: Constant values and those which vary with altitude.

\section{A. Constant factors}

Provision is made for the input of scaling factors so that an aerodynamic coefficient array may be altered without the necessity of having to enter another complete set of data. This capability facilitates performing parametric studies in which the sensitivity of vehicle and/or control system performance on variations in aerodynamic coefficients is examined. There are 28 scale factors corresponding to each of the 28 aerodynamic coefficients given in Tables I or II. Each coefficient is multiplied by the corresponding scale factor. The scale factors are input as follows:

Scale factor card, type 1

Format (A10)

Card Cols. Contents 1-5 SCALE

(2) Scale factor card, type 2

Format (8F10.0)

Card Cols. Contents

1-10, etc. Each of the 28 scale factors are entered in fields of 10 . (Thus requiring 4 data cards.)

B. Altitude-dependent factors

Under this option, the scaling factors are entered as tabular functions of altitude, thus allowing the aerodynamic coefficients to be functions of altitude. This provides a capability for closely simulating the effects of fin ablation, trim-angle variation, boundary-layer transition, etc. There are 28 altitude-dependent scale factors corresponding to each of the 28 aerodynamic coefficients given in Tables I or II. A linear interpolation is performed between table entries in accordance with the instantaneous value of altitude. Each coefficient is multiplied by the altitude-dependent factor. Note also that under this option, the effects of a coefficient may be initiated (or stopped) at a specified altitude. There are two types of cards used to enter the altitude-dependent aerodynamic scale factors: 
(1)

Altitude scale factor card, type 1

Format $(\mathrm{A} 10,2 \mathrm{I5})$

Card Cols. Contents

1-6 ASCALE

11-15 $\mathrm{K}$ Coefficient input number (Tables I or II) for which scale factor is being used.

16-20 NSC Number of values to be read in (NSC pairs of points will be expected).

(2) Altitude scale factor card, type 2 (as required)

Format $(8 \mathrm{~F} 10.0)$

\begin{aligned} Card Cols. & Contents \\ \hline $1-10 &$ Altitude (ft) \\ $11-20 &$ Scale factor \\ $21-30 &$ Altitude \\ $31-40 &$ Scale factor \\ $41-50 &$ Altitude \\ $51-60 &$ Scale factor \\ $61-70 &$ Altitude \\ $71-80 &$ Scale factor \end{aligned}

C. Altitude-dependent fin-scale factors and fin-trim angles

Provision is made to allow the total fin aerodynamic coefficients to vary with altitude. This provides a capability for modeling changes in fin effectiveness due to uniform as well as differential fin ablation, etc. Also under this option, altitude-dependent fin-trim angles may be input. This arises from considerations of asymmetric fin erosion which produces a bias in the fin force coefficients in the form of an effective fin-trim cant angle. These data must be input with altitude monotonically increasing, and are limited to a maximum of 20 pairs of points.

The input necessary to enter these fin effects is as follows 
(1) Fin-effects card, type 1

Card Cols. Contents

1-6 FSCALE

11-15 K Type of fin effects input

1 - Fin 1 scale factor

2 - Fin 2 scale factor

3 - Fin 1 trim angle - deg

4 - Fin 2 trim angle - deg

16-20 NSC Number of values to be entered (NSC pairs of points will be expected)

(2) Fin-effects card, type 2

\begin{aligned} Card Cols. & Contents \\ \hline $1-10 &$ Altitude (ft) \\ $11-20 &$ Scale factor or trim angle (deg) \\ $21-30 &$ Altitude \\ $31-40 &$ Scale factor or trim angle (deg) \\ $41-50 &$ Altitude \\ $51-60 &$ Scale factor or trim angle (deg) \\ $61-70 &$ Altitude \\ $71-80 &$ Scale factor or trim angle (deg) \end{aligned}

D. Altitude-dependent off set of vehicle center-of-mass

In addition to the initial vehicle center-of-mass lateral off sets which appear on the MASS card, the center-of-mass is also allowed to vary laterally with altitude. This provides a capability for modeling heatshield mass loss and the resulting lateral center-of-mass displacement. Two factors are used to model the center-of-mass shift: 1) a radial distance $R_{m}$ from the longitudingal axis (body $X$ axis), 2) the angular orientation, $\phi_{m}$, of the radial offset measured positively clockwise from the body $Y$ axis when the missile is viewed from the rear. These quantities are illustrated in Figure 14. 


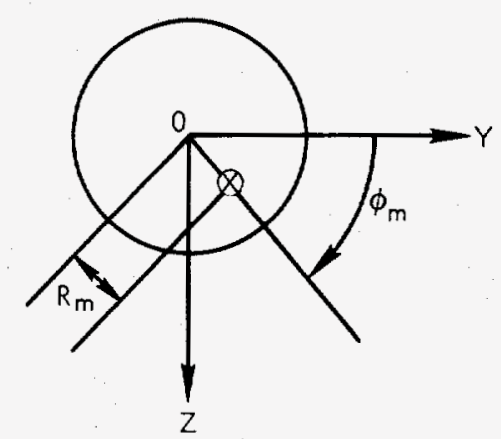

Figure 14. Center-of-Mass Variation

The data are entered in the same fashion as the fin effects data and have the same restrictions (a maximum of 20 pairs of points with altitude monotonically increasing). The input cards are described below:

(1) Center-of-mass offset card, type 1

Card Cols. Contents
$1-6$
MSCALE
$11-15$
$K \quad$ type of input
1 - Radial offset, $R_{m}$
2 - Angular orientation, $\phi_{\mathrm{m}}$ (deg)
$16-20$
NSC
Number of values to be entered (NSC pairs of points will be expected)

(2) Center-of-mass offset card, type 2

$\begin{array}{cl}\text { Card Cols. } & \text { Contents } \\ 1-10 & \text { Altitude }(\mathrm{ft}) \\ 11-20 & \mathrm{R}_{\mathrm{m}} \text { or } \phi_{\mathrm{m}} \\ 21-30 & \text { Altitude }(\mathrm{ft}) \\ 31-40 & \mathrm{R}_{\mathrm{m}} \text { or } \phi_{\mathrm{m}} \\ 41-50 & \text { Altitude }(\mathrm{ft}) \\ 51-60 & \mathrm{R}_{\mathrm{m}} \text { or } \phi_{\mathrm{m}} \\ 61-70 & \text { Altitude }(\mathrm{ft}) \\ 71-80 & \mathrm{R}_{\mathrm{m}} \text { or } \phi_{\mathrm{m}}\end{array}$


To illustrate the method of input for all altitude-dependent effects discussed previously, an altitude-dependent, center-of-mass offset is used. Given the center-of-mass displacements and orientations in the body system as shown in $\mathrm{T}$ able $\mathrm{V}$, a listing of the necessary data cards for input to the program is provided in Figure 15.

TABLE V

ALTITUDE-DEPENDENT EFFECTS DATA

(Center-of-Mass Location)

$\begin{array}{rrr}\text { Altitude (kft) } & \text { Radial Offset (ft) } & \text { Orientation Angle (deg) } \\ 0 & 0.0035 & 90 \\ 15 & 0.0030 & 90 \\ 25 & 0.0020 & 90 \\ 40 & 0.0020 & 120 \\ 53 & 0.0010 & 60 \\ 75 & 0.0010 & 90 \\ 85 & 0.0008 & 90 \\ 87 & 0.0000 & 0 \\ 400 & 0.0000 & 0\end{array}$




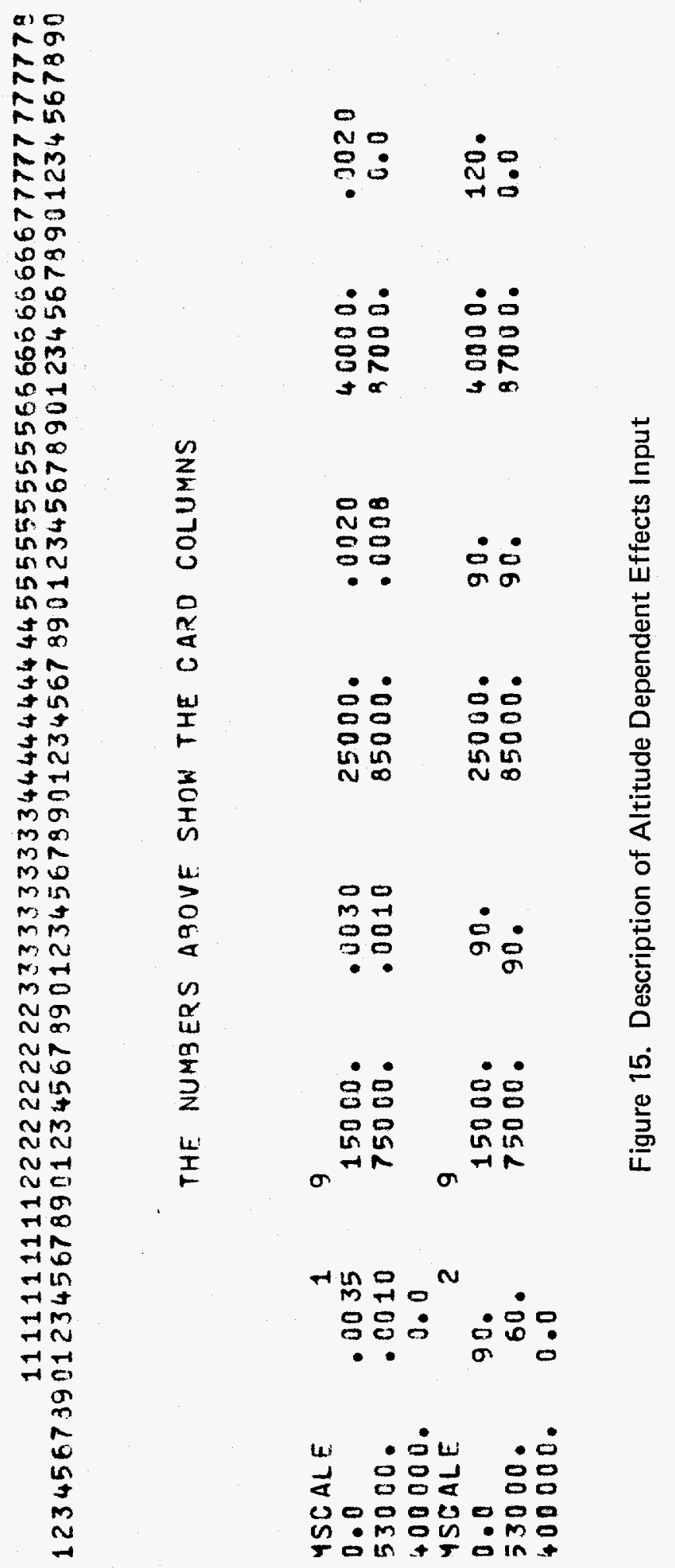




\section{RUN Card}

At the end of all input for a particular trajectory calculation, a RUN card must be entered to signify that all data have been provided and to initiate computation.

\section{Card Cols. $\quad$ Contents}

$$
\text { 1-3 RUN }
$$

Description of Input for Sample Problem

The details of the various data inputs as described in the foregoing sections are perhaps best illustrated by setting up a sample problem. A listing of the data cards necessary to run a hypothetical trajectory computation is given in Figure 16. The data shown do not necessarily conform to any physical system, but are presented merely to illustrate input. Included in Figure 16 are all of the different input forms previously described. 
11111111112222222222333333333344444444445555555555665665665677777777779 12345679901234567990123456799012345679901234567990123455799612345579901234567390

THE NUMBEPS AQOVE SHOW THE CARD COLUMNS

\begin{tabular}{|c|c|c|c|c|c|c|c|}
\hline TITLE & SA MPLE & TQA JECTORY & COMPUTATI & & & & \\
\hline $\begin{array}{l}\text { ZONTROL } \\
\text { YASS }\end{array}$ & $1.25^{20}$ & $\begin{array}{c}2 \\
3.4887\end{array}$ & $\begin{array}{r}1 \\
2.202\end{array}$ & $\begin{array}{l}111111 \\
0.0\end{array}$ & $\begin{array}{l}111111 \\
.008667\end{array}$ & & \\
\hline $\begin{array}{l}\text { INERT IA } \\
\text { START }\end{array}$ & $\begin{array}{l}3229 \\
0.0\end{array}$ & $\begin{array}{l}3.4881 \\
3.1236 \\
.005\end{array}$ & $\begin{array}{l}3.1150 \\
300139 .\end{array}$ & $\begin{array}{l}02420 \\
21449.5\end{array}$ & $\begin{array}{l}0.0 \\
-24.946\end{array}$ & $\begin{array}{l}0.0 \\
0.00\end{array}$ & 0.0 \\
\hline ANGLE & 0.0 & 0.0 & 37.7 & 0.0 & 0.0 & & \\
\hline $\begin{array}{l}\text { POLL1 } \\
\text { POLL2 }\end{array}$ & $\begin{array}{r}.03108 \\
-.5641\end{array}$ & $\begin{array}{l}78.0 \\
-.5641\end{array}$ & $\begin{array}{l}2.0 \\
0.0\end{array}$ & $\begin{array}{l}: 23103 \\
0.0\end{array}$ & $\begin{array}{l}78.0 \\
.14015\end{array}$ & $\begin{array}{l}2.0 \\
0.14018\end{array}$ & \\
\hline ₹OL L 3 & .281 & .231 & .365 & .365 & .323 & .323 & \\
\hline $\begin{array}{l}\text { २OL L4 } \\
\text { २OLL5 }\end{array}$ & $\begin{array}{l}-.3975 \\
5.0\end{array}$ & $\begin{array}{l}-.8975 \\
-5.0\end{array}$ & $\begin{array}{l}0.0 \\
5.0\end{array}$ & $\begin{array}{l}C .0 \\
-5.0\end{array}$ & -.5625 & .5625 & \\
\hline ROL L6 & & & & & & & \\
\hline $\begin{array}{l}\text { POLL7 } \\
\text { SCALE }\end{array}$ & 10.0 & 0.0 & 190. & 0.0 & & & \\
\hline-1.129 & $1 \cdot 0$ & 1.3 & 1.0 & $1 \cdot 0$ & -1.0 & 1.0 & 1.0 \\
\hline $\begin{array}{l}1.0 \\
1.0\end{array}$ & $\begin{array}{l}1.0 \\
1.0\end{array}$ & $\begin{array}{l}1.0 \\
1.0\end{array}$ & $\begin{array}{l}1 . ? \\
1.0\end{array}$ & $\begin{array}{l}1.00 \\
1.0\end{array}$ & $\begin{array}{l}1.0 \\
1.0\end{array}$ & $\begin{array}{l}1.0 \\
1.0\end{array}$ & $\begin{array}{l}1.0 \\
1.0\end{array}$ \\
\hline 1.0 & 1.0 & 1.0 & 1.0 & 1.0 & 1.0 & & \\
\hline $\begin{array}{l}\text { ASC ALE } \\
0.0\end{array}$ & $1 \cdot 3^{27}$ & ${ }^{4} 85000$. & 1.0 & 87000. & 0.0 & 400000. & 0.0 \\
\hline FSCALE & -1 & 10 & & & & & \\
\hline $\begin{array}{l}0.0 \\
+0000 . \\
30000 .\end{array}$ & $\begin{array}{l}.45 \\
1.15 \\
1.75\end{array}$ & $\begin{array}{l}10000 . \\
50000 . \\
400000 .\end{array}$ & $\begin{array}{l}.65 \\
1.25 \\
1.75\end{array}$ & $\begin{array}{l}20000 . \\
60000 .\end{array}$ & $\begin{array}{l}.85 \\
1.5\end{array}$ & $\begin{array}{l}30000 . \\
70000 .\end{array}$ & $\begin{array}{l}1.0 \\
1.70\end{array}$ \\
\hline
\end{tabular}

Figure 16. Description of Input for Sample Problem 


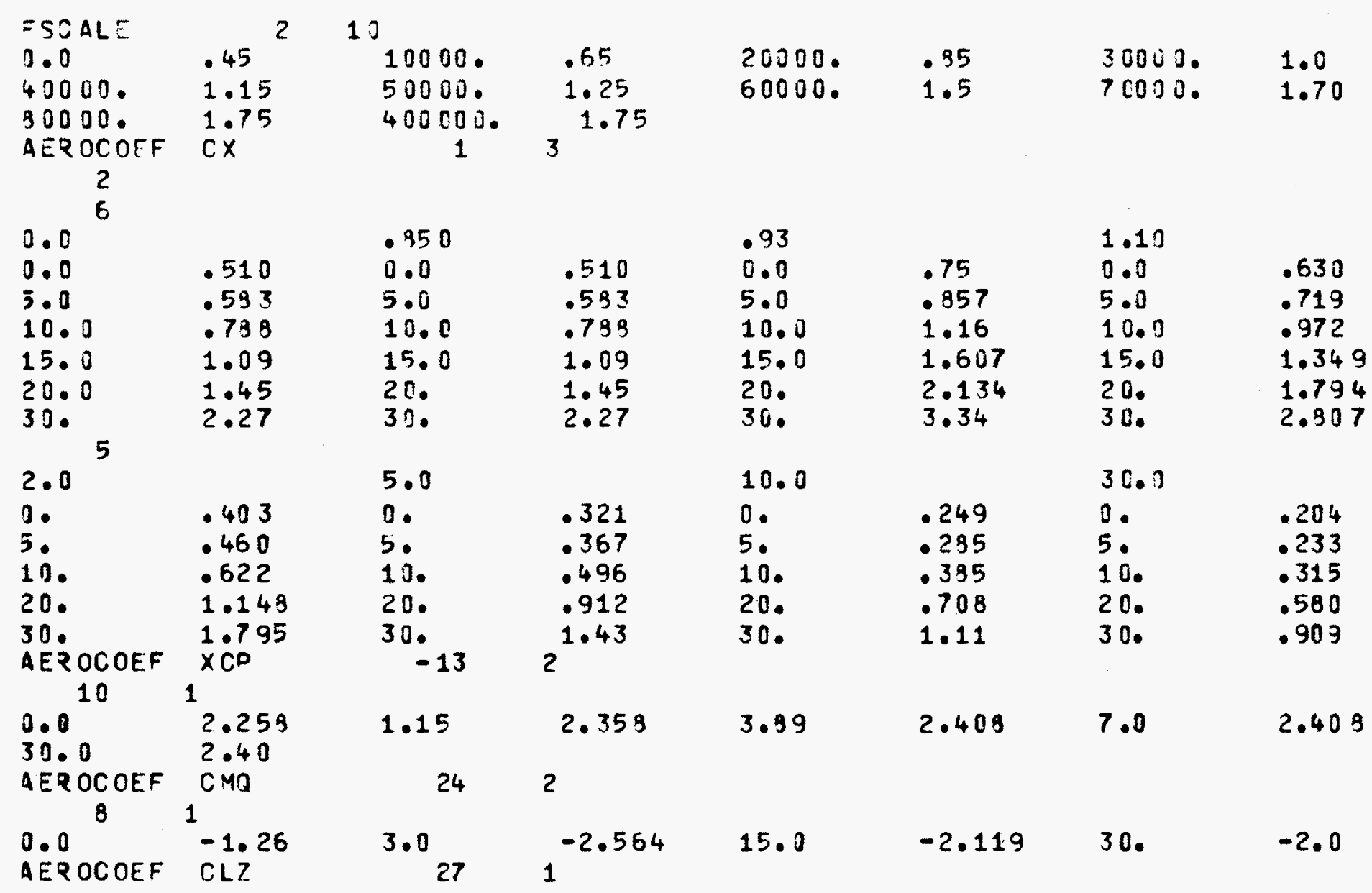

Figure 16. (Continued) 


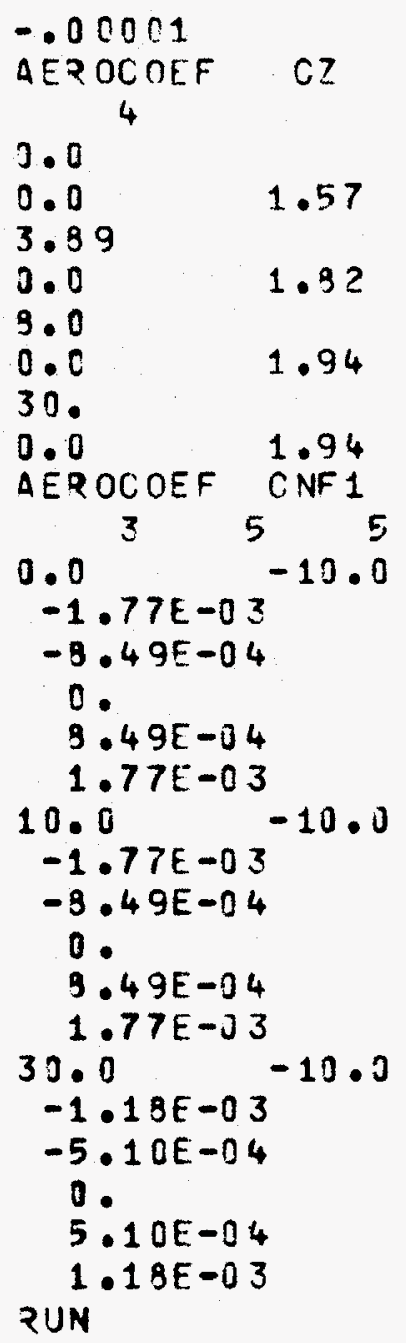

$-10$. $-10.0$

0.

1. $1 D E-03$

$7.68 E-04$

$-5.0$

$-5.71 E-03$

$-4 \cdot 21 E-03$

0 .

4.21E-03

$5.71 E-03$

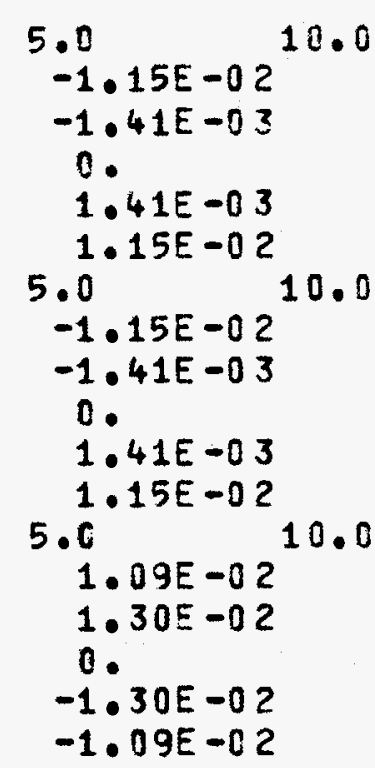

Figure 16. (Continued) 
Description of Output

At the start of the trajectory simulation, a listing of the aerodynamic coefficients is provided. This is followed by a printout of each of the control and initialization parameters, the vehicle and roll-control system (when applicable) physical properties, and the aerodynamic coefficient scaling factors. After the trajectory computations are completed, an editing phase is entered in which tabular listings of various trajectory variables as well as printer plots and/or CRT plots of these variables versus time or altitude are given. The standard output table (Table VI) is printed, one data point for each print interval according to the print option indicators which appear on the CONTROL card. This listing is followed by any or all of the supplementary output tables shown in Table VII as specified as well as plots of each set of variables versus time or altitude as indicated on the CONTROL card. In Tables VI and VII, each variable is given a numerical designation. When appropriate, the variables are written on disc or magnetic tape in the order shown. 


\section{TABLE VI \\ STANDARD OUTPUT VARIABLES}

\begin{tabular}{|c|c|c|}
\hline Symbol & Description & Units \\
\hline $\mathrm{t}$ & Time & s \\
\hline $\mathrm{x}$ & Downrange & $\mathrm{ft}$ \\
\hline $\mathrm{y}$ & Altitude & ft \\
\hline $\mathrm{z}$ & Cross range & ft \\
\hline V & Velocity & $\mathrm{ft} / \mathrm{s}$ \\
\hline M & Mach number & \\
\hline Q & Dynamic pressure & $1 \mathrm{~b} / \mathrm{ft}^{2}$ \\
\hline$\vec{\alpha}$ & Total angle of attack & $\operatorname{deg}$ \\
\hline$\hat{\phi}$ & Aerodynamic roll angle & rad \\
\hline$\alpha$ & Angle of attack & deg \\
\hline$\beta$ & Angle of sideslip & $\operatorname{deg}$ \\
\hline$\dot{\mathrm{y}}$ & Accelerations in inertial frame & $\mathrm{ft} / \mathrm{s}^{2}$ \\
\hline $\mathrm{p}$ & Roll rate & $\mathrm{rad} / \mathrm{s}$ \\
\hline $\mathrm{p}_{\text {crit }}$ & $\begin{array}{l}\text { Critical frequency } \\
\text { (vehicle undamped natural pitch frequency) }\end{array}$ & $\mathrm{rad} / \mathrm{s}$ \\
\hline$\rho_{1}$ & & $\mathrm{ft}$ \\
\hline$\dot{\rho}_{1}$ & & $\mathrm{ft} / \mathrm{s}$. \\
\hline$\rho_{2}$ & Control mass displacements and velocities & $\mathrm{ft}$ \\
\hline$\dot{\mathrm{p}}_{2}$ & & $\mathrm{ft} / \mathrm{s}$ \\
\hline $\begin{array}{l}\delta_{1} \\
\delta_{2}\end{array}$ & Fin deflections & $\begin{array}{l}\text { deg } \\
\operatorname{deg}\end{array}$ \\
\hline
\end{tabular}


TABLE VII

SUPPLEMENTARY OUTPUT VARIABLES

\section{$\underline{\text { Set } 1}$}

\begin{tabular}{|c|c|c|c|}
\hline Variable No. & Symbol & Description & Units \\
\hline 1 & - & Time & $\mathrm{s}$ \\
\hline 2 & $\mathrm{x}$ & Downrange & \\
\hline 3 & $\mathrm{y}$ & Altitude & $\mathrm{ft}$ \\
\hline 4 & $\mathrm{z}$ & Crossrange & \\
\hline 5 & $\mathrm{~V}$ & Velocity & $\mathrm{ft} / \mathrm{s}$ \\
\hline 6 & $\mathrm{M}$ & Mach number & \\
\hline 7 & $Q$ & Dynamic pressure & $\mathrm{lb} / \mathrm{ft}^{2}$ \\
\hline 8 & $\vec{\alpha}$ & Total angle of attack & $\operatorname{deg}$ \\
\hline 9 & $\hat{\phi}$ & Aerodynamic roll angle & rad \\
\hline 10 & $\alpha$ & Angle of attack & $\operatorname{deg}$ \\
\hline 11 & $\beta$ & Angle of sideslip & $\operatorname{deg}$ \\
\hline 12 & $\mathrm{p}$ & Roll rate & $\mathrm{rad} / \mathrm{s}$ \\
\hline 13 & $\mathrm{p}_{\text {crit }}$ & $\begin{array}{l}\text { Critical frequency } \\
\text { (undamped natural pitch frequency) }\end{array}$ & $\mathrm{rad} / \mathrm{s}$ \\
\hline
\end{tabular}

Set 2 (roll-control system variables)

$\begin{array}{lllc}14 & \rho_{1} & \text { Control mass (1) displacement } & \mathrm{ft} \\ 15 & \dot{\rho}_{1} & \text { Control mass (1) velocity } & \mathrm{ft} / \mathrm{s} \\ 16 & \ddot{\rho}_{1} & \text { Control mass (1) acceleration } & \mathrm{ft} / \mathrm{s}^{2} \\ 17 & \rho_{2} & \text { Control mass (2) displacement } & \mathrm{ft} \\ 18 & \dot{\rho}_{2} & \text { Control mass (2) velocity } & \mathrm{ft} / \mathrm{s} \\ 19 & \ddot{\rho}_{2} & \text { Control mass (2) acceleration } & \mathrm{ft} / \mathrm{s}^{2} \\ 20 & \delta_{1} & \text { Fin 1 displacement } & \mathrm{deg} \\ 21 & \delta_{2} & \text { Fin 2 displacement } & \mathrm{deg}\end{array}$


Set 3 (translational and angular velocities)

\begin{tabular}{|c|c|c|c|}
\hline Variable No. & Symbol & Description & Units \\
\hline 22 & $\dot{x}$ & \multirow{4}{*}{ Velocities in inertial frame } & \multirow{3}{*}{$\mathrm{ft} / \mathrm{s}$} \\
\hline 23 & $\dot{\mathrm{y}}$ & & \\
\hline 24 & $\dot{\mathrm{z}}$ & & \\
\hline 25 & $\mathrm{u}$ & & \multirow{3}{*}{$\mathrm{ft} / \mathrm{s}$} \\
\hline 26 & $\mathrm{v}$ & \multirow[t]{2}{*}{ Components of velocity in body axes } & \\
\hline 27 & $\mathrm{w}$ & & \\
\hline 28 & $\mathrm{p}$ & \multirow{3}{*}{$\begin{array}{l}\text { Angular velocity components in } \\
\text { body axes }\end{array}$} & \multirow{3}{*}{$\mathrm{rad} / \mathrm{s}$} \\
\hline 29 & $q$ & & \\
\hline 30 & $\mathbf{r}$ & & \\
\hline
\end{tabular}

Set 4 (translational and angular accelerations)

31

32

33

34

35

36

37

38

39 $\ddot{x}$ $\left.\begin{array}{c}x \\ \ddot{y} \\ \ddot{z}\end{array}\right\}$

$\dot{u}$

$\left.\begin{array}{c}\dot{u} \\ \dot{v} \\ \dot{w}\end{array}\right\}$

$\left.\begin{array}{c}\dot{\mathrm{p}} \\ \dot{\mathrm{q}} \\ \dot{\mathrm{r}}\end{array}\right\}$
Accelerations in inertial frame

$\mathrm{ft} / \mathrm{s}^{2}$

Components of acceleration in body axes

Angular acceleration in body axes $\mathrm{rad} / \mathrm{s}^{2}$ 
TABLE VII (Continued)

Set 5 (aerodynamic coefficients and g-loading)

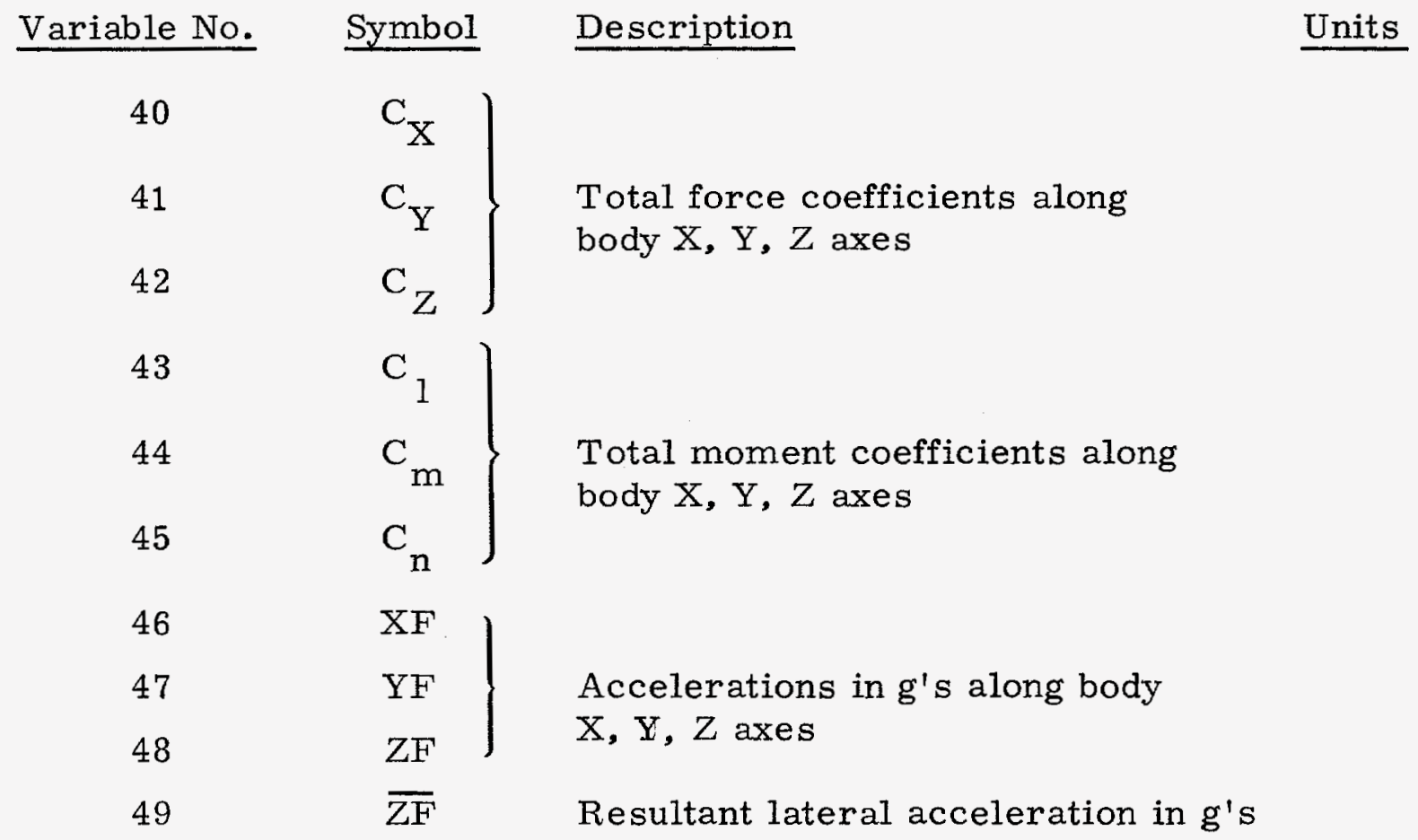

Set 6 (space orientation parameters)

50

51

52

53

54

55

56

57

58

59

60

$\left.\begin{array}{l}\theta \\ \psi \\ \phi\end{array}\right\}$

Euler pitch, yaw, and roll angles

$\operatorname{deg}$

Versor components

Derivatives of versor components

$1 / \mathrm{s}$ 
TABLE VIII

STANDARD PLOT VARIABLES

(plotted versus time or altitude)

Symbol

$\vec{\alpha}$

$\hat{\phi}$

$\mathrm{p}$ and $\mathrm{p}_{\text {crit }}$

$\delta_{1}$ and $\delta_{2}$
Description

Total angle of attack

Aerodynamic roll angle

Roll rate and vehicle undamped natural pitch frequency

Fin deflection angles
Units

deg

rad

$\mathrm{rad} / \mathrm{s}$

deg 
•

• 


\section{APPENDIX A -- Summary of Governing Equations}

1. Vehicle Equations of Motion

- Linear and angular velocities in body system

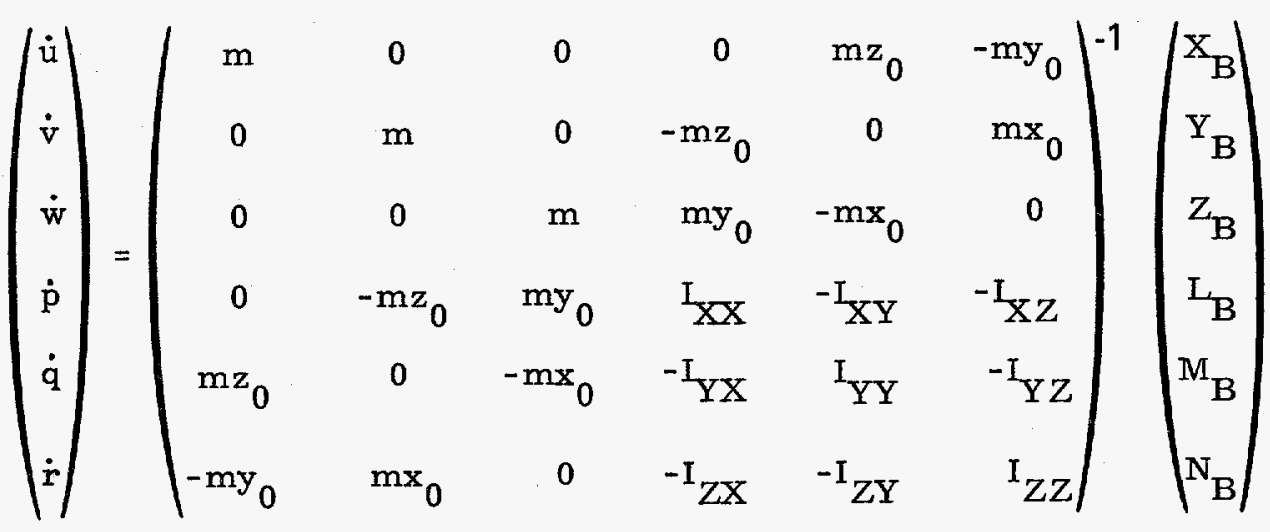

$$
\left(\begin{array}{c}
\mathrm{X}_{\mathrm{B}} \\
\mathrm{Y}_{\mathrm{B}} \\
\mathrm{Z}_{\mathrm{B}} \\
\mathrm{L}_{\mathrm{B}} \\
\mathrm{M}_{\mathrm{B}} \\
\mathrm{N}_{\mathrm{B}}
\end{array}\right)=\left(\begin{array}{c}
\mathrm{F}_{\mathrm{X}} \\
\mathrm{F}_{\mathrm{Y}} \\
\mathrm{F}_{\mathrm{Z}} \\
\mathrm{L} \\
\mathrm{M} \\
\mathrm{N}
\end{array}\right)+\left(\begin{array}{c}
\mathrm{Q}_{\mathrm{X}} \\
\mathrm{Q}_{\mathrm{Y}} \\
\mathrm{Q}_{\mathrm{Z}} \\
\mathrm{Q}_{\mathrm{L}} \\
\mathrm{Q}_{\mathrm{M}} \\
\mathrm{Q}_{\mathrm{N}}
\end{array}\right)
$$




$$
\left(\begin{array}{c}
F_{X} \\
F_{Y} \\
F_{Z} \\
L \\
M \\
N
\end{array}\right)=Q S\left(\begin{array}{c}
C_{X} \\
C_{Y} \\
C_{Z} \\
C_{1} d \\
C_{m} d \\
C_{n} d
\end{array}\right)+m g\left(\begin{array}{c}
-A_{X Y} \\
-A_{Y Y} \\
-A_{Z Y} \\
z_{0} A_{X Y}-y_{0} A_{Z Y} \\
x_{0} A_{Z Y}-z_{0} A_{X Y} \\
y_{0}{ }_{X Y}-x_{0} A_{Y Y}
\end{array}\right)
$$

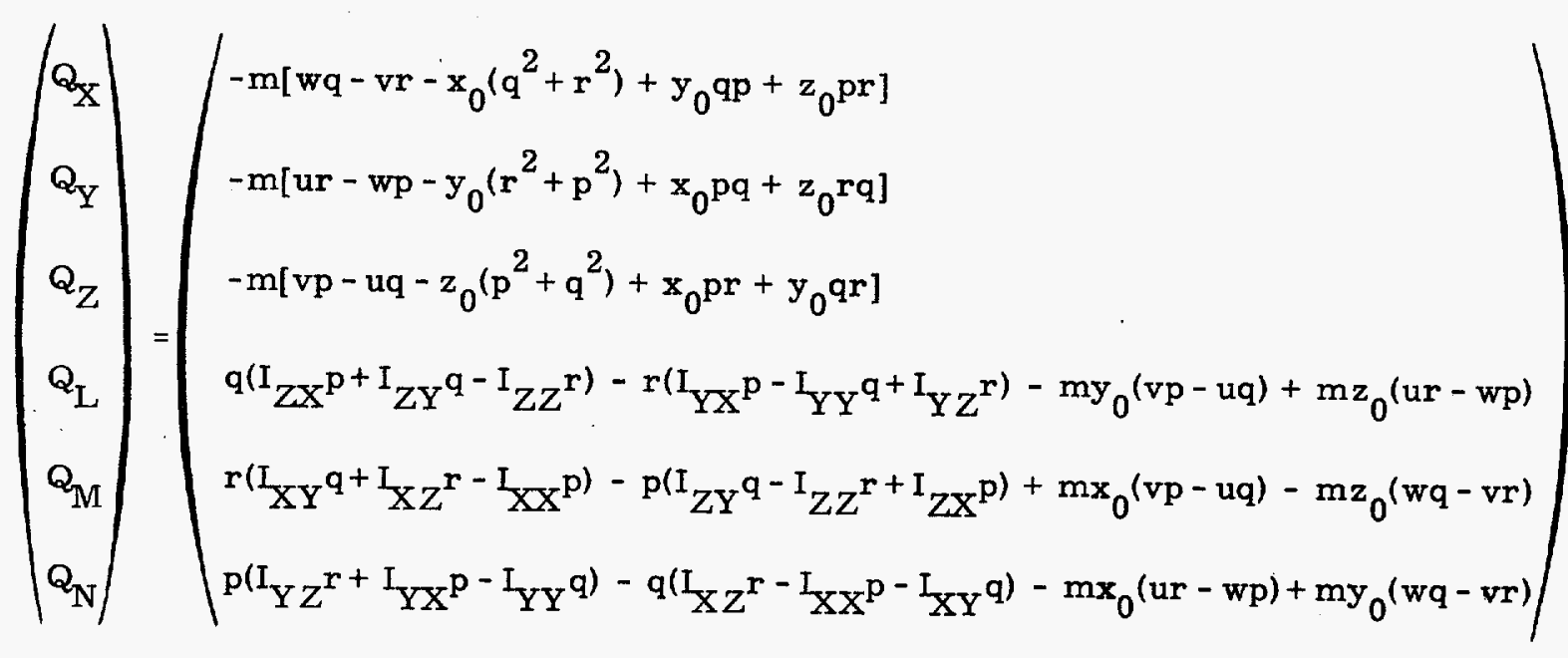


2. Equations of Control Mass Motion for Each Control Mass

- Linear and angular velocities in control system coordinates

$$
\left(\begin{array}{c}
u_{c}, \dot{u}_{c} \\
v_{c}, \dot{v}_{c} \\
w_{c}, \dot{w}_{c} \\
p_{c}, \dot{p}_{c} \\
q_{c}, \dot{q}_{c} \\
r_{c}, \dot{r}_{c}
\end{array}\right)\left(\begin{array}{cccccc}
\cos \psi_{c} & \sin \psi_{c} \cos \phi_{c} & \sin \psi_{c} \sin \phi_{c} & 0 & 0 & 0 \\
-\sin \psi_{c} & \cos \psi_{c} \cos \phi_{c} & \cos \psi_{c} \sin \phi_{c} & 0 & 0 & 0 \\
0 & -\sin \phi_{c} & \cos \phi_{c} & 0 & 0 & 0 \\
0 & 0 & 0 & \cos \psi_{c} & \sin \psi_{c} \cos \phi_{c} & \sin \psi_{c} \sin \phi_{c} \\
0 & 0 & 0 & -\sin \psi_{c} & \cos \psi_{c} \cos \phi_{c} & \cos \psi_{c} \sin \phi_{c} \\
0 & 0 & 0 & -\sin \phi_{c} & \cos \phi_{c}
\end{array}\right)\left(\begin{array}{l}
u, \dot{u} \\
v, \dot{v} \\
q, \dot{p} \\
q \\
r, \dot{\mathrm{q}}
\end{array}\right)
$$

- Control mass acceleration

$$
\begin{aligned}
\ddot{\rho}= & {\left[-\mathrm{k}\left(\rho-\rho_{0}\right)-\mathrm{c} \dot{\rho}+\mathrm{F}_{\text {AERO }}-\mathrm{f}\right] / \overline{\mathrm{m}} } \\
& -\left(\dot{\mathrm{v}}_{\mathrm{c}}+\mathrm{u}_{\mathrm{c}} r_{\mathrm{c}}-\mathrm{w}_{\mathrm{c}} \mathrm{p}_{\mathrm{c}}\right)-\mathrm{x}_{\mathrm{m}}\left(\mathrm{p}_{\mathrm{c}} \mathrm{q}_{\mathrm{c}}+\dot{r}_{\mathrm{c}}\right) \\
& -\mathrm{z}_{\mathrm{m}}\left(\mathrm{r}_{\mathrm{c}} \mathrm{q}_{\mathrm{c}}-\dot{\mathrm{p}}_{\mathrm{c}}\right)+\rho\left(\mathrm{r}_{\mathrm{c}}^{2}+\mathrm{p}_{\mathrm{c}}^{2}\right)
\end{aligned}
$$

- Control mass friction force

$$
f=\left(\bar{f}+\bar{\mu} F_{F I N}+\hat{\mu} X_{F}\right) \operatorname{Sign}(\dot{\rho})
$$

- Aerodynamic feedback force

$$
\mathrm{F}_{\mathrm{AERO}}=\mathrm{C}_{\mathrm{N}_{\mathrm{F}}} \in \phi_{\mathrm{L}} \mathrm{QS}
$$

- Geometric fin cant

$$
\begin{aligned}
\delta & =\delta_{0}-\phi_{L}\left(\rho-\rho_{I}\right) \\
\phi_{L} & =\left(\frac{\delta_{0}-\delta_{\min }}{\rho_{\max }-\rho_{I}}\right)
\end{aligned}
$$


3. Kinematic Relations

- Vehicle velocity in space

$$
\left(\begin{array}{l}
x \\
y \\
z
\end{array}\right)=\left(\begin{array}{ccc}
A_{X X} & A_{Y X} & A_{Z X} \\
A_{X Y} & A_{Y Y} & A_{Z Y} \\
A_{X Z} & A_{Y Z} & A_{Z Z}
\end{array}\right)\left(\begin{array}{l}
u \\
v \\
w
\end{array}\right)
$$

- Versor derivatives

$$
\left(\begin{array}{l}
\dot{\lambda}_{0} \\
\dot{\lambda}_{1} \\
\dot{\lambda}_{2} \\
\dot{\lambda}_{3}
\end{array}\right)=-\frac{1}{2}\left(\begin{array}{cccc}
o & \mathrm{p} & \mathrm{q} & \mathrm{r} \\
-\mathrm{p} & \mathrm{o} & -\mathrm{r} & \mathrm{q} \\
-\mathrm{q} & \mathrm{r} & \mathrm{o} & -\mathrm{p} \\
-\mathrm{r} & -\mathrm{q} & \mathrm{p} & \mathrm{o}
\end{array}\right)\left(\begin{array}{l}
\lambda_{0} \\
\lambda_{1} \\
\lambda_{2} \\
\lambda_{3}
\end{array}\right)
$$

- Versor normalization

$$
\lambda_{0}^{2}+\lambda_{1}^{2}+\lambda_{2}^{2}+\lambda_{3}^{2}=1
$$

- Transformation matrix (relates space variables to body variables)

$$
\left(\begin{array}{lll}
\mathrm{A}_{\mathrm{XX}} & { }_{\mathrm{YX}} & { }^{\mathrm{A}_{\mathrm{ZX}}} \\
\mathrm{A}_{\mathrm{XY}} & { }_{\mathrm{YY}} & { }^{\mathrm{A}_{Z Y}} \\
\mathrm{~A}_{\mathrm{XZ}} & { }_{\mathrm{YZ}} & { }^{\mathrm{A}_{Z Z}}
\end{array}\right)=\left(\begin{array}{lll}
2\left(\lambda_{0}^{2}+\lambda_{1}^{2}\right)-1 & 2\left(\lambda_{1} \lambda_{2}+\lambda_{0} \lambda_{3}\right) & 2\left(\lambda_{1} \lambda_{3}-\lambda_{0} \lambda_{2}\right) \\
2\left(\lambda_{1} \lambda_{2}-\lambda_{0} \lambda_{3}\right) & 2\left(\lambda_{0}^{2}+\lambda_{2}^{2}\right)-1 & 2\left(\lambda_{2} \lambda_{3}+\lambda_{0} \lambda_{1}\right) \\
2\left(\lambda_{1} \lambda_{3}+\lambda_{0} \lambda_{2}\right) & 2\left(\lambda_{2} \lambda_{3}-\lambda_{0} \lambda_{1}\right) & 2\left(\lambda_{0}^{2}+\lambda_{3}^{2}\right)-1
\end{array}\right)
$$

- Vehicle orientation in space

$$
\left(\begin{array}{l}
\psi \\
\theta \\
\phi
\end{array}\right)=\left(\begin{array}{ll}
\tan ^{-1} & \left(\mathrm{~A}_{\mathrm{XZ}} / \mathrm{A}_{\mathrm{XX}}\right) \\
\sin ^{-1} & \left(\mathrm{~A}_{\mathrm{XY}}\right) \\
\tan ^{-1} & \left(-\mathrm{A}_{\mathrm{ZY}} / \mathrm{A}_{\mathrm{YY}}\right)
\end{array}\right)
$$


4. Aerodynamic Variables

$$
\begin{aligned}
& \vec{\alpha}=\tan ^{-1} \sqrt{\frac{v^{2}+w^{2}}{u^{2}}} \\
& \hat{\phi}=\tan ^{-1}\left(\frac{v}{w}\right) \\
& \vec{q}=\sqrt{q^{2}+r^{2}} \\
& \tilde{\phi}=\tan ^{-1}\left(\frac{-r}{q}\right) \\
& V_{T}=\sqrt{u^{2}+v^{2}+w^{2}} \\
& V_{C}=\sqrt{v^{2}+w^{2}}
\end{aligned}
$$

5. Atmospheric Properties

$$
\begin{aligned}
\rho & =\rho(\mathrm{h}) \\
\mathrm{Q} & =\frac{1}{2} \rho(\mathrm{h}) \mathrm{V}_{\mathrm{T}}^{2} \\
\mathrm{~V}_{\mathrm{S}} & =\mathrm{V}_{\mathrm{S}}(\mathrm{h}) \\
\mathrm{M} & =\mathrm{V}_{\mathrm{T}} / \mathrm{V}_{\mathrm{S}}
\end{aligned}
$$

6. Aerodynamic Coefficients

- Fin force coefficient expansion

$$
\begin{aligned}
& \mathrm{C}_{\mathrm{N}_{\mathrm{F}}}=\mathrm{C}_{\mathrm{F}_{1}}+\mathrm{C}_{\mathrm{F}_{2}} \sin \hat{\phi}+\mathrm{C}_{\mathrm{F}_{3}} \cos \hat{\phi}+\mathrm{C}_{\mathrm{F}_{4}} \sin 2 \hat{\phi}+\mathrm{C}_{\mathrm{F}_{5}} \cos 2 \hat{\phi} \\
& \mathrm{C}_{\mathrm{F}_{\mathrm{i}}}=\sum_{j=0}^{5} \mathrm{C}_{\mathrm{F}_{i j}} \vec{\alpha}^{\mathrm{j}} \\
& \mathrm{C}_{\mathrm{F}_{\mathrm{i}}}=\mathrm{C}_{\mathrm{F}_{\mathrm{i}}}(\mathrm{M}, \mathrm{h})
\end{aligned}
$$




$$
\left(\begin{array}{c}
C_{X} \\
C_{Y} \\
C_{Z}
\end{array}\right)=\left(\begin{array}{ccc}
C_{X}-C_{D_{F_{1}}}-C_{D_{F_{2}}} & 0 & 0 \\
C_{Y_{\epsilon}+C_{L_{F_{1}}}-C_{L_{F_{2}}}} C_{Y_{0}}+C_{Y_{p}}^{p d / 2 V} & C_{Z_{0}} \\
C_{Z_{\epsilon}} & C_{Z_{0}} & -C_{Y_{0}}+C_{Y_{p}} p d / 2 V
\end{array}\right)\left(\begin{array}{c}
1 \\
\cos \hat{\phi} \\
\sin \hat{\phi}
\end{array}\right)
$$

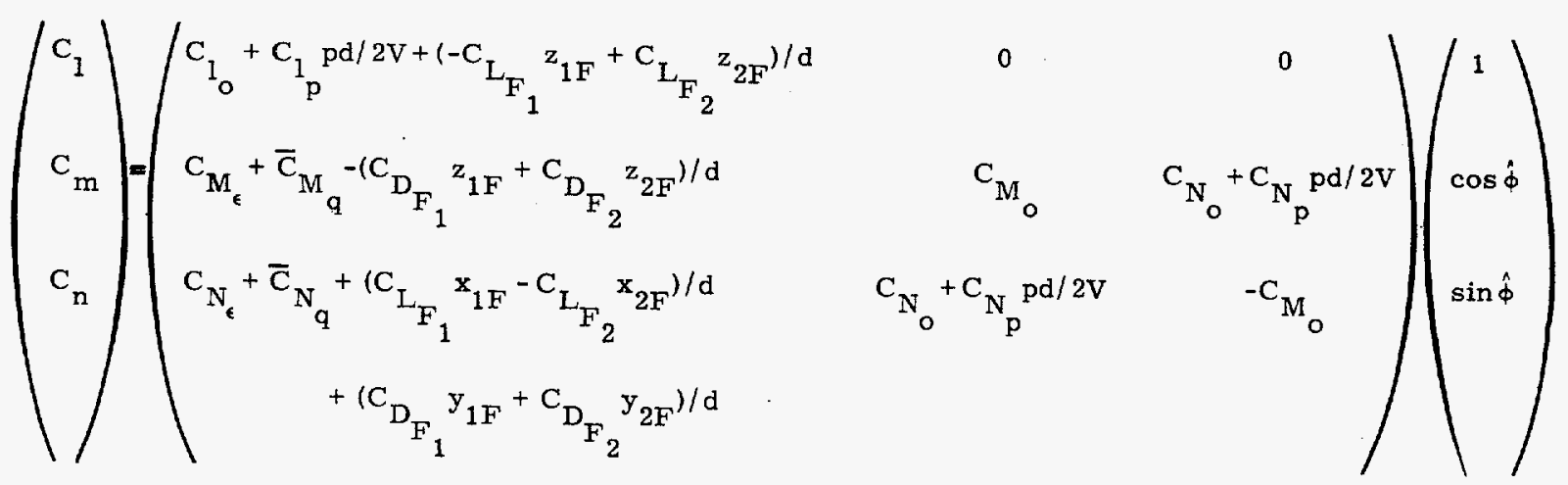

$$
\begin{aligned}
& \overline{\mathrm{C}}_{\mathrm{m}_{\mathrm{q}}}=\mathrm{C}_{\mathrm{m}_{\mathrm{q}}} \overrightarrow{\mathrm{q}} \mathrm{d} / 2 \mathrm{~V} \cos \tilde{\phi} \\
& \overline{\mathrm{C}}_{\mathrm{n}_{\mathrm{q}}}=\mathrm{C}_{\mathrm{m}_{\mathrm{q}}} \overrightarrow{\mathrm{q}} \mathrm{d} / 2 \mathrm{~V} \sin \tilde{\phi}
\end{aligned}
$$

$$
\left(\begin{array}{l}
\mathrm{C}_{\mathrm{L}_{\mathrm{F}_{1}}} \\
\mathrm{C}_{\mathrm{D}_{\mathrm{F}_{1}}} \\
\mathrm{C}_{\mathrm{L}_{\mathrm{F}_{2}}} \\
\mathrm{C}_{\mathrm{D}_{\mathrm{F}_{2}}}
\end{array}\right)=\left(\begin{array}{cccc}
\cos \delta_{1} & -\sin \delta_{1} & 0 & 0 \\
\sin \delta_{1} & \cos \delta_{1} & 0 & 0 \\
0 & 0 & \cos \delta_{2} & -\sin \delta_{2} \\
0 & 0 & \cos \delta_{2} & \cos \delta \\
0 & & &
\end{array}\right)\left(\begin{array}{l}
\mathrm{C}_{\mathrm{N}_{F_{1}}} \\
\mathrm{C}_{\mathrm{A}_{F_{1}}} \\
\mathrm{C}_{\mathrm{N}_{\mathrm{F}_{2}}} \\
\mathrm{C}_{\mathrm{A}_{F_{2}}}
\end{array}\right)
$$




\section{References}

1. J. K. Kryvoruka, A Formulation of the Equations of Motion for Flight Vehicles with Semi-Passive Roll Control Systems, Sandia Laboratories, SCL-RR-720007, April 1972.

2. J. K. Kryvoruka, Aero- and Flight Dynamics of Finned Reentry Vehicles, Sandia Laboratories (to be published).

3. T. J. Weber, Design and Lab Testing of a Hydraulically Controlled Roll Control Mechanism - A Preflight Report, Sandia Laboratories (to be published).

4. T. J. Weber, C. T. Yokomizo, Sandia Laboratories, unpublished paper.

5. J. K. Kryvoruka, Roll Control Resonance Test Vehicle (RCRTV-1) Preflight Test Report, SCL-DR-720038, Sandia Laboratories, May 1972.

6. J. K. Kryvoruka, Sandia Laboratories, unpublished paper.

7. W. T. Ashurst, Fin Aerodynamic Estimates Which Include Crossflow Effects, Sandia Laboratories, SCL-DR-70-137, March 1971.

8. J. H. Jones, E. C. Knox, J. C. Donaldson, Static Stability Tests on a Finned Nine-Degree Cone at Mach Numbers 8 and 13, Arnold Engineering Development Center, Tennessee, AEDC-TR-71-4, January 1971.

9. J. K. Kryvoruka, Sandia Laboratories, unpublished paper.

10. D. H. Platus, Dynamic Instability of Finned Missiles Caused by Unequal Effectiveness of Windward and Leeward Fins, AIAA Paper Presented at 8th Aerospace Sciences Meeting, New York, January 1970 .

11. J. K. Kryvoruka, SIXD: A Trajectory Computer Program to Determine the Motions of Asymmetric Missiles, Sandia Laboratories, SCL-RR-70-121, February 1971. 
12. D. H. Platus, Performance Evaluation of the Centrifugally Operated Fin Roll Control System, Aerospace Corporation, SAMSO-TR-71-250, TR-0172 (2240-30)-2, September 1971.

13. T. J. Weber, C. T. Yokomizo, E. A. English, Sandia Laboratories, unpublished paper. 


\section{DISTRIBUTION:}

AEC/TIC, Oak Ridge, Tennessee (3)

Aerospace Corporation

E1 Segundo, Ca.

Attn: D. H. Platus

Aerospace Corporation

San Bernardino, Ca.

Attn: R. F. Ross

LASL

Los Alamos, New Mexico

Attn: R. A. Gentry (1)

J. McNalley

W. E. Nelson, LLL, L125

Technical Information Division, LLL, L3

D. B. Shuster, 1200

W. C. Myre, 1210

R. L. Peurifoy, 1220

H. W. Schmitt, 1225

C. H. Mauney, 1530

T. B. Lane, 1540

R. G. Clem, 1730

W. C. Hines, 1733

V. L. Dugan, 1734

A. Y. Pope, 5600

R. C. Maydew, 5620

E. C. Rightley, 5623

W. R. Barton, 5624

A. E. Hodapp, 5625

H. R. Vaughn, 5625

G. G. Wilson, 5625

W. H. Curry, 5645

G. C. Newlin, 6011 (3)

T. B. Cook, Jr., 8000

L. Gutierrez, 8100

J. F. Barham, Jr., 8130

J. B. Wright, 8131

A. F. Baker, 8137

D. E. Gregson, 8150 
R. A. Baroody, 8160

G. E. Brandvold, 8170

A. S. Rivenes, 8175

J. K. Kryvoruka, 8176 (10)

G. E. Strandin, 8176

R. J. Tockey, 8176

T. J. Weber, 8176

J. D. Gilson, 8177

J. M. Alcone, 8178

R. E. Humphrey, 8178

G. R. Otey, 8178

R. W. Phillips, 8178

C. S. Selvage, 8180

C. H. DeSelm, 8200

B. F. Murphey, 8300

J. W. Weihe, 8320

J. Mansfield, 8321

R. A. McHugh, 8321

J. N. Rogers, 8321

P. L. Leary, 8321

R. K. Saltgaver, 8321

L. D. Brandt, 8324

T. S. Gold, 8324

J. D. Hankins, 8325

A. N. Blackwell, 8350

R. N. Everett, 8351

A. R. Willis, 8351

D. L. Hartley, 8354

W. C. Scrivner, 8400

J. D. Benton, 8411

J. M. Nielson, 8411

Technical Information Division I, 3151

Technical Correspondence and Reports File, 3142-1 (4)

D. L. Rasmussen, 8321/Central Technical File, 8232-2

Central Technical File, 8232-2 (4) 